\title{
A Divided Old Age through Research on Digital Technologies
}

\section{ARIANNA POLI}

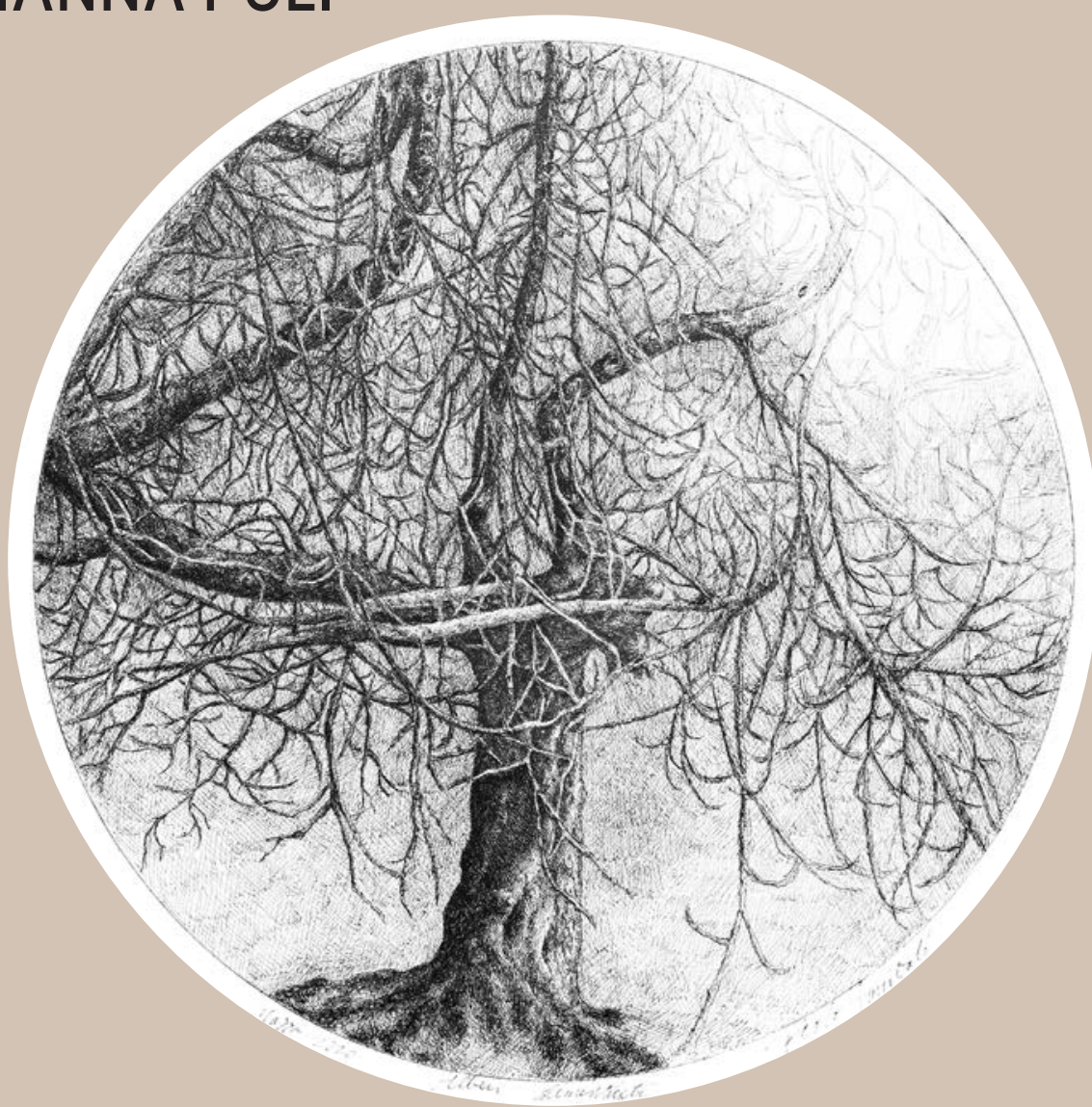





\title{
A Divided Old Age through Research on Digital Technologies
}

\author{
Arianna Poli
}

Division Ageing and Social Change Department of Culture and Society Faculty of Arts and Sciences Linköping University, Sweden Linköping 2021 
Linköping Studies in Arts and Sciences $•$ No. 814

At the Faculty of Arts and Sciences at Linköping University, research and doctoral studies are carried out within broad problem areas. Research is organized in interdisciplinary research environments and doctoral studies mainly in graduate schools. Jointly, they publish the series Linköping Studies in Arts and Sciences. This thesis comes from the Division Ageing and Social Change at the Department of Culture and Society.

Distributed by:

Department of Culture and Society

Linköping University

58183 Linköping

Author: Arianna Poli

Title: A Divided Old Age through Research on Digital Technologies

Cover illustration: Annibali, Paolo (2020). Alberi

Dimenticati (Forgotten Trees) [China ink on paper]. In: P. Annibali, Quello che so -Chine su carta (What I know - China ink on paper). Urbino: Edizioni QuattroVenti.

Edition 1:1

ISSN 0282-9800

ISBN 978-91-7929-032-0 (print)

ISBN 978-91-7929-046-7 (PDF)

https://doi.org/ 10.3384/9789179290467

(C) Arianna Poli, 2021

\begin{tabular}{|l|l}
\hline$(\mathrm{cc})$ EY \\
\hline
\end{tabular} International License.

https://creativecommons.org/licenses/by/4.0/

Printed in Sweden by LiU-tryck, 2021

Articles have been reprinted with the permission of the respective copyright owners. 
To My Splendid Family 



\section{Abstract}

This thesis aims at contributing to the understanding of digital inequalities among older people, by studying the involvement of older people in research on digital technologies. Some mechanisms driving old age digital inequalities are well known. For instance, people with lower social positions tend to have lower digital skills, to face technology accessibility and affordability issues, and, thus, to engage less with digital technologies compared to their counterparts. However, less attention has been paid to issues related to research and development of digital technologies, such as the involvement of older people in research evaluating new digital technologies, for understanding digital inequalities. Previous studies indicate that participants and nonparticipants in research are different one another, with the former being younger, reporting higher educational levels, having better health status than the non-participants. This may bias research outcomes and lead to incorrect conclusions on the utility of digital technologies. The objective of this thesis is to investigate the link between the involvement of older people in digital technology evaluations and the research outcomes. Healthcare is used as exemplifying context in which digital technologies are largely evaluated and used. In Study I, participation in digital health research is conceptualised, and a research tool for identifying and measuring selective participation is developed. In Study II and III, factors associated with participation in two digital health intervention studies are analysed. In Study IV, the impact of selective participation on the research outcomes of a digital health study is identified, measured, and corrected. Thesis findings show that participation of older people in digital health research is selective by age, gender, health status, job level, and digital skills, and can indicate a mechanism for digital inequalities. Selective participation biases research outcomes by overemphasising the intervention effects of the over-represented groups over those of the 
under-represented groups. It can cause an overestimation of the positive effects of digital health technologies due to the under-representation of those groups who do not benefit from the intervention. This promotes digital technologies which increase exclusion risks for some groups of older people and reinforce old age digital and social inequalities. Weighting procedures can be used for mitigating the impact of this mechanism on the research outcomes of intervention studies on digital technologies.

Keywords: digital inequalities, involvement in research, biased outcomes, old age exclusion, old age social inequalities, older people. 


\section{Sammanfattning}

Denna avhandling syftar till att bidra till förståelsen av digital ojämlikhet bland äldre genom att studera äldre människors deltagande $\mathrm{i}$ forskning om digital teknik. Vissa mekanismer som driver den digitala ojämlikheten bland äldre är välkända. Till exempel tenderar personer med lägre sociala positioner att ha lägre digitala färdigheter, stöta på problem med tekniktillgänglighet och kostnader, och därmed engagera sig mindre i digital teknik jämfört med personer med högre sociala positioner. Mindre uppmärksamhet har dock ägnats åt frågor som rör forskning och utveckling av digital teknik, t.ex. äldres deltagande i forskning som utvärderar ny digital teknik. Tidigare studier visar att deltagare och ickedeltagare i forskning är olika varandra: deltagarna är yngre, har högre utbildningsnivå och bättre hälsotillstånd än icke-deltagarna. Detta kan snedvrida forskningsresultaten och leda till felaktiga slutsatser om nyttan av digital teknik. Syftet med denna avhandling är att undersöka sambandet mellan äldre människors deltagande i digitala teknikutvärderingar och forskningsresultaten. Hälso-och sjukvård används som exemplifierande sammanhang. I Studie I konceptualiseras deltagandet i digital hälsoforskning och ett forskningsverktyg för att identifiera och mäta selektivt deltagande utvecklas. I Studie II och III analyseras faktorer som är förknippade med deltagande i två digitala hälsointerventionsstudier. I Studie IV identifieras, mäts och korrigeras effekterna av selektivt deltagande på forskningsresultaten från en digital hälsostudie. Avhandlingsresultatet visar att äldre människors deltagande i digital hälsoforskning är selektivt utifrån ålder, kön, hälsotillstånd, arbetsnivå och digitala färdigheter, och kan indikera en mekanism för digital ojämlikhet. Selektivt deltagande snedvrider forskningsresultaten genom att man överbetonar de överrepresenterade gruppernas interventionseffekter jämfört med de underrepresenterade. Det kan leda till en överskattning av de positiva effekterna av digital hälsoteknik på 
grund av underrepresentationen av de grupper som inte drar nytta av interventionen. Detta främjar därmed digital teknik som ökar risken för utestängning av vissa grupper av äldre och stärker den digitala och sociala ojämlikheten bland äldre. Viktningsförfaranden kan användas för att mildra effekterna av denna mekanism på forskningsresultaten av interventionsstudier på digital teknik.

Nyckelord: digital ojämlikhet, forskningsdeltagande, snedvridna resultat, exkludering av äldre, social ojämlikhet bland äldre, äldre. 


\section{Riassunto}

Questa tesi ha l'obiettivo di contribuire alla comprensione delle disuguaglianze digitali tra gli anziani attraverso lo studio del loro coinvolgimento nella ricerca sulle tecnologie digitali. Alcuni dei meccanismi che generano disuguaglianze digitali in età anziana sono ben noti. Ad esempio, persone con posizioni sociali più basse tendono ad avere minori capacità digitali, a riscontrare problemi di accessibilità pratica ed economica e, pertanto, ad utilizzare meno le tecnologie digitali rispetto ai gruppi sociali più avvantaggiati. Tuttavia, finora la letteratura ha rivolto un'attenzione più limitata ai meccanismi legati alla ricerca sulle nuove tecnologie digitali e al loro ruolo nel determinare e, eventualmente, perpetuare disuguaglianze digitali. A tal riguardo, una questione poco investigata è ad esempio il coinvolgimento delle persone anziane negli studi che valutano nuove tecnologie digitali. Precedenti ricerche indicano che gli individui che partecipano e coloro che non partecipano a studi di ricerca differiscono tra di loro. I primi sono tipicamente più giovani, riportano livelli più alti di istruzione e mostrano migliori livelli di stato di salute rispetto ai secondi. Queste discrepanze tra partecipanti e non partecipanti negli studi di ricerca potrebbero generare una distorsione dei risultati della ricerca (bias), nonché indurre a conclusioni scientifiche errate che si applicherebbero solo a specifici gruppi di individui e non ad altri. L'obiettivo di questa tesi è di investigare il legame che esiste tra il coinvolgimento degli anziani nelle ricerche che valutano nuove tecnologie digitali e i risultati che si ottengono da tali ricerche. L'ambito sanitario è utilizzato come contesto esemplificativo in cui viene condotta molta ricerca sulle tecnologie digitali. Nello Studio I viene concettualizzata la partecipazione agli studi che valutano tecnologie digitali per la salute e viene sviluppato uno strumento per l'identificazione e la misurazione della partecipazione selettiva. Negli Studi II e III i fattori associati alla partecipazione sono analizzati in due 
interventi che valutano tecnologie digitali per la salute. Nello Studio IV viene identificato, misurato e corretto l'impatto della partecipazione selettiva sui risultati di un intervento basato su una tecnologia digitale per la salute. I risultati di questa tesi indicano che la partecipazione delle persone anziane a studi che valutano nuove tecnologie digitali per la salute è selettiva per età, genere, stato di salute, livello lavorativo e competenze digitali, e che la partecipazione selettiva può essere un meccanismo che alimenta disuguaglianze digitali. La partecipazione selettiva distorce i risultati delle valutazioni delle tecnologie digitali per la salute, enfatizzando gli effetti dei gruppi sovrarappresentati a discapito di quelli dei gruppi sottorappresentati. Questo può causare una sovrastima degli effetti positivi delle tecnologie digitali per la salute, dovuta alla sottorappresentazione di quei gruppi che non traggono benefici dall'intervento, e può promuovere tecnologie digitali che aumentano $\mathrm{i}$ rischi di esclusione e le disuguaglianze digitali e sociali. Procedure dette di weighting (ponderazione statistica) possono essere applicate per mitigare l'impatto del meccanismo di partecipazione selettiva sui risultati degli interventi di salute digitale.

Parole chiave: disuguaglianze digitali, coinvolgimento nella ricerca, risultati distorti (bias), esclusione in età anziana, disuguaglianze sociali in età anziana, anziani. 


\section{Acknowledgements}

Over the past years, I have been incredibly lucky to be surrounded by wonderful people who have, in several different ways, supported my ambition to become a scientist and helped me with the completion of this Ph.D. work. I would like to thank everyone who was there for me along the way of my Ph.D. journey for the comments, the criticisms, the exchanges of ideas, and the influence on my thinking and my research. However, some people deserve a special mention in this section.

First and foremost, I wish to thank my supervisor Andreas MotelKlingebiel for giving me the chance to learn so much from him, for providing me with numerous opportunities to grow professionally much faster than I could imagine, for profoundly believing in my abilities as researcher, for patiently listening to my ideas and interests, and for being an extraordinary source of support, inspiration, and constructive criticism. Your guidance has been indeed invaluable to me. Then, special thanks go to Susanne Kelfve, my brilliant co-supervisor, for being always willing and never too busy to do some work together, for empowering me with her positive energy, for supporting me to keep my focus, and for enthusiastically advising and encouraging my ambitions. I feel extremely privileged to have worked so closely to two outstanding and generous scholars as you are. Together, you challenged, stimulated, and inspired my thinking, and made my journey to the Ph.D. truly exciting.

I also would like to thank all the co-authors who, beyond my supervisors, co-operated with me on the four studies composing this thesis, Katarina Berg, Lina Homman, Leonie Klompstra, Ingemar Kåreholt "Pingo", Tiny Jaarsma, and Anna Strömberg. I learned much from each one of you, and I am genuinely glad to have collaborated with 
you all during the past years. Also, I would like to express my gratitude to the opponents and commentators who participated in my doctoral seminars throughout the years of my Ph.D. studies - Harald Rohracher, Stefan Fors, Sofi Fristedt, Lars-Christer Hydén, Annika T. Larsson, Ulli Samuelsson, Alexander Seifert - for their insightful comments and stimulating discussions which brought this Ph.D. thesis to a higher level. Additionally, I would like to extend my sincere thanks to all the colleagues (both current and former ones) at the Division Ageing and Social Change for their valuable influence on my work, for their contagious passion for science, and for their treasured support while I worked on my Ph.D. project. It has been a great pleasure to be surrounded by all of you!

Thanks should also go to the institutions that made this Ph.D. work possible and to the scientific networks that enriched my Ph.D. education, starting with Linköping University and the Division Ageing and Social Change where I work since 2015, the Swedish Research Council for Health, Working Life and Welfare (FORTE) and the Swedish Research Council (VR) that funded the ICT4Self-Care programme within which I conducted this Ph.D. work, as well as the Swedish National Graduate School on Ageing and Health (SWEAH) and the COST Action (CA15122) Reducing Old-Age Social Exclusion in Europe: Collaborations in Research and Policy (ROSEnet) to which I was affiliated during the years of my Ph.D. studies and which gave me the fantastic opportunity to meet and be inspired by brilliant minds from across the world.

Then, I would like to thank the Italian artist, Paolo Annibali, for the beautiful cover illustration of this book Alberi dimenticati (Forgotten trees) which, I believe, represents splendidly the spirit of this research.

Writing a doctoral dissertation is not solely a professional affair. None of this would have been possible without my splendid family - my sister Angelica, my mum Tiziana, and my dad Francesco - whose endless love, positivity, and constant encouragement kept me motivated, focused, and confident in anything I had done and planned to do for my career. No words can express my deepest gratitude to you three. My accomplishments exist, first of all, because I have you. Then, many thanks go to all my friends around Europe but especially to my dearest girls, Eva, Ludia, Martina, and Sarah, for being an incredible source of 
positive energy, genuine support, and happy distractions. You are all extraordinary. Last but not least, a million thanks go to Francesco, my precious partner and best reader, for supporting, listening, inspiring, advising, and encouraging me in any way he could, every day, since the day I decided I wanted to become a scientist. He alone knows how essential his support and influence has been to me at every stage of this work.

Thank you all. Without you, I would not be here now, writing these words. Ad meliora et maiora semper!

San Benedetto del Tronto, Italy

August 2021

Arianna Poli 


\section{List of original publications}

This dissertation comprises four original publications which are referred to in the text as Study I, II, III, and IV. The reader can find the publications at the end of this book.

I. Poli, A., Kelfve, S., \& Motel-Klingebiel, A. (2019). A Research Tool for Measuring Non-Participation of Older People in Research on Digital Health. BMC Public Health, 19(1), 1487. https://doi.org/10.1186/s12889-019-7830-x

II. Poli, A., Kelfve, S., Klompstra, L., Jaarsma, T., Strömberg, A., \& Motel-Klingebiel, A. (2020). Prediction of (Non)Participation of Older People in Digital Health Research: Exergame Intervention Study. Journal of Medical Internet Research, 22(6), e17884. https://doi.org/10.2196/17884

III. Poli, A., Kelfve, S., Berg, C., \& Motel-Klingebiel, A. (under review, minor revisions) Old-Age Diversity is Under-represented in Digital Health Research: Findings from the Evaluation of a Mobile Phone System for Post-Operative Progress Monitoring in Sweden. Ageing \& Society.

IV. Poli, A., Kåreholt, I., Kelfve, S., Berg, K., Homman, L., \& MotelKlingebiel, A. (manuscript). Non-Participation in a Digital Health Intervention Study among Older Adults: Biased Outcomes and the Effect of Weighting. 
xviii 


\section{Table of Contents}

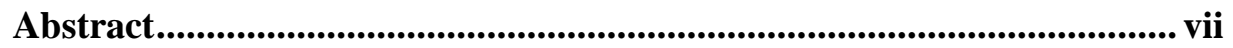

Sammanfattning.................................................................................................. ix

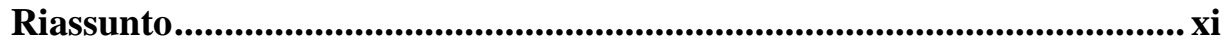

Acknowledgements ........................................................................................

List of original publications.........................................................................

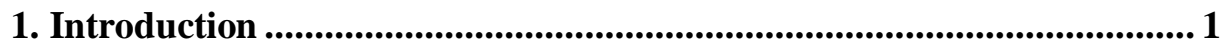

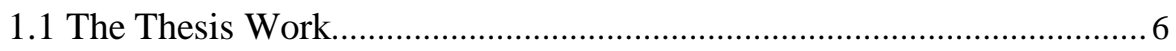

1.2 Aim and Research Questions ........................................................... 7

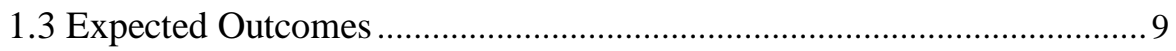

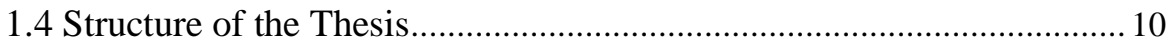

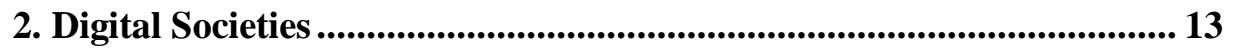

2.1 Digital Technologies in the Service Provision .................................... 14

3. Ageing and Social Inequality in Digital Societies ...................................... 19

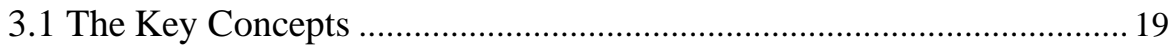

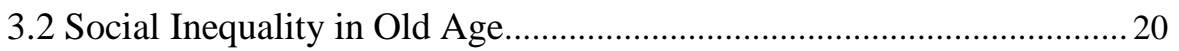

3.3 The Mechanism of Selective Participation in Research on Digital

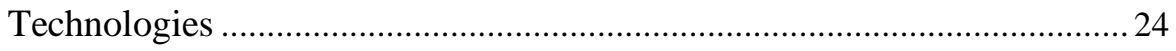

4. Digital Technologies between Potential and Inequalities........................ 25

4.1 Potential of Digital Technologies in Healthcare..................................... 25

4.2 Challenges through Digital Health Technologies................................... 26

5. Evaluation of Digital Technologies as an Inequality Mechanism .......... 33

5.1 Involving Older People in Research and Development of Digital

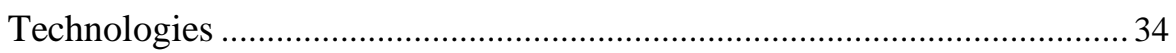

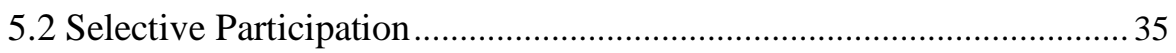

5.3 Selective Participation as a Methodological Problem ............................. 41 
6. Empirical Research, Materials, and Methods.......................................... 45

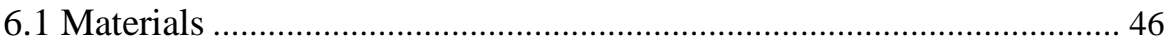

6.2 A Multi-Step Approach to Participation and the NPART Research Tool

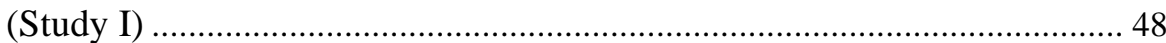

6.3 Examining Participation in the HF-Wii Intervention Study (Study II). 51

6.4 Examining Participation in the MIRAS Intervention Study (Study III) 52

6.5 Correcting the Impact of Selective Participation (Study IV) ............... 55

7. Summary of the Results .............................................................................5 59

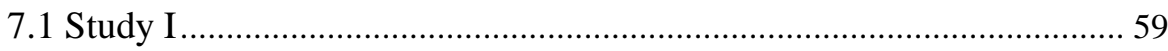

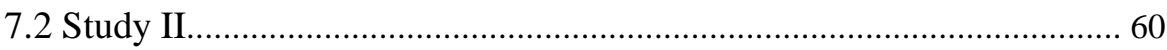

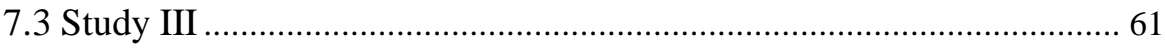

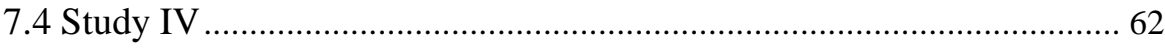

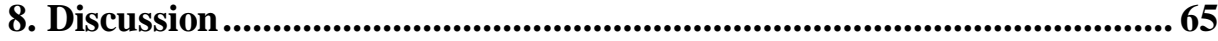

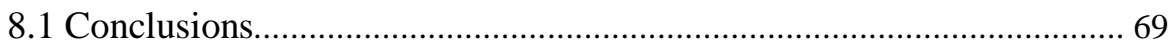

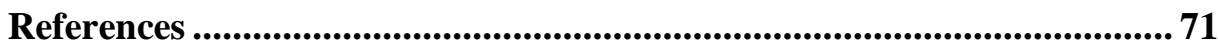




\section{Chapter 1 \\ Introduction}

Growing social inequalities are a pressing issue of our time. Life chances, risks, and outcomes are unequally distributed within and between societies, new sources of social inequalities emerge and sum up with old ones, and the gap between groups of individuals reinforces and widens (Alvaredo et al., 2018; OECD, 2015; United Nations Department of Economic and Social Affairs, 2020). Individual outcomes, in their positive and negative relative value, cumulate and intersect one another over the life course, and are eventually carried into later life where they result in diverse individual experiences of ageing (Baars et al., 2016; Dannefer, 2018; Holman and Walker, 2020; OECD, 2017b; Wildman, 2020). Such unequal ageing occurs within changing societal contexts in which new inequality factors arise and contribute to reinforce existing disparities. An example for this is the rapid digitalisation and spread of digital technologies in various spheres of our societies. Although the recent technological advancements has overall brought significant benefits to our societies, they have been contributing to replicate and worsen social inequalities (United Nations Department of Economic and Social Affairs, 2020). 
Many scholars agree upon the fact that recent social inequalities in countries of the Western world started to rise in connection with changes in redistribution and reorganisation of the welfare systems, which have progressively occurred during the past four decades (Atkinson, 2015; Esping-Andersen, 1999; Marx, Nolan and Olivera, 2015). After a period of expansion and consolidation of the welfare states following the Second World War, political decisions have gradually changed directions towards, for example, limiting redistribution and social protection, increasing the degree of privatisation (Atkinson, 2015; Baars et al., 2016; Quadagno, Kail and Shekha, 2011; Wildman, 2020). The public welfare systems were deemed as inefficient, not cost-effective, and not necessary to guarantee the well-being of the individuals (Atkinson, 2015; Quadagno, Kail and Shekha, 2011). In parallel to this, the rate of accumulated capital returns has been growing much faster than the rate of the economic growth. This powerful macro mechanism has contributed to much increase the levels of social inequalities, which can hardly be counteracted by less protective and less redistributive welfare systems (Boushey, DeLong and Steinbaum, 2017; Piketty, 2014, 2020). All these macro processes associated with social inequalities have occurred in a time of pronounced societal transformations, such as population ageing, globalisation and international migrations, which are markedly redefining the composition of Western societies, intensifying the diversity that characterises them (Baars et al., 2016; Hyde and Higgs, 2016; Phillipson, 2013; Torres, 2015, 2019; Victor, 2010).

Mortality has been reduced, and people live longer lives (Bloom et al., 2015; Crimmins, 2004; Victor, 2010). This represents a great success in modern history, but it comes along with challenges, such as health-related ones. Along with longer lives, the prevalence of chronic diseases and multimorbidity has increased, and more older individuals live with diseases and show complex health-related needs than in the past (Bloom et al., 2015; Crimmins and Beltrán-Sánchez, 2010; Lloyd, 2012; Tavares and Zantomio, 2017). More economic resources are needed for arranging a healthcare provision that is able to meet such a complex range of healthrelated needs. Beyond, globalisation brings new forces into play. The individual experience of old age is no longer limited within a local dimension in which nations and communities organise themselves, but it is also situated in a global context and exposed to the influence of global actors and institutions (Baars et al., 2016; Hyde and Higgs, 2016). Along 


\section{Introduction}

with that, increasingly more people live and grow old in countries which are not the ones where they were born, and this increases the diversity of individual backgrounds and needs in the society (Phillipson, 2013; Torres, 2019). Overall, European countries are facing the challenging task of dealing with a population which is highly diverse and show heterogeneous needs and experiences (Phillipson, 2013), and have to define responses based on trends and influences which are global (Hyde and Higgs, 2016). In such a complex context, some groups of individuals have become increasingly more vulnerable to suffer from the impact of, for instance, digitalisation and digital technologies, that can reduce their chances of reaching good standards of living (Grenier and Phillipson, 2020; Scharf and Keating, 2012).

Digital technology use is involved in various spheres of individuals' lives and, thus, in the access to services (European Commission, 2020b; OECD, 2016, 2017a; United Nations, 2020; United Nations Department of Economic and Social Affairs, 2020). Digital technologies are increasingly more often used as means for providing services of different kinds, and often embed cutting-edge technologies such as artificial intelligence (AI). This reshapes the way individuals participate and approach several systems in the society (Eccles, 2020; Evangelista, Guerrieri and Meliciani, 2014; United Nations Department of Economic and Social Affairs, 2020). Promoting a digital society mirrors the policy ambition of improving the current systems and making them able to address the needs of a population which is more and more diverse, in a sustainable way (European Commission, 2016, 2018, 2020b; OECD, 2017a; Pirhonen et al., 2020; United Nations, 2020). All individuals are expected to access and use digital technologies in order to participate in the society and meet their needs (Mort, Roberts and Callén, 2013).

Healthcare service provision has also been affected by the advent of digital technologies (Bennett and Glasgow, 2009; Eccles, 2020; European Commission, 2018; Mort, Roberts and Callén, 2013; United Nations Department of Economic and Social Affairs, 2020). Ranging from websites and mobile applications to remote monitoring and rehabilitation, digital technologies in healthcare (which I will refer to as digital health technologies in this thesis) are increasingly more applied and evolve continuously according to the newest technological advancements, such as virtual and augmented reality, robotics, sensors, including those based on AI (Czaja, 2017; Eccles, 2020; Merrell and Doarn, 2018; Scott et al., 
2020). Sustained by dedicated policies, stimulated by the accumulation of technological advances, and supported by research findings, digital health is seen as a solution for offering good quality healthcare services under the condition of a growing demand for care (Eccles, 2020; European Commission, 2018, 2020b; World Health Organization, 2017). Analogue services are progressively replaced by digital ones, and individuals are expected to have the necessary skills, to be adequately equipped, and to be willing to use the new services (Eccles, 2020; Mort, Roberts and Callén, 2013). Although the use of digital technologies in the provision of healthcare services has shown potential for improving healthcare and its organisation, it poses critical challenges with regards to the inclusion of those groups of people who do not have access and do not use regularly digital technologies (Czaja, 2017; Eccles, 2020; Fang et al., 2018; Olsson, Samuelsson and Viscovi, 2017; Pirhonen et al., 2020; Seifert, Hofer and Rössel, 2018; United Nations Department of Economic and Social Affairs, 2020).

Older people are one of the main user groups of healthcare services (Robinson et al., 2015; Terraneo, 2015) and, thus, largely affected by a digital shift in healthcare. However, the use of digital technologies is unequally distributed among them (König, Seifert and Doh, 2018; OECD, 2017a; Olsson and Viscovi, 2020). This holds true even in notoriously more digitally advanced countries, according to the European Digital Economy and Society Index (DESI) (European Commission, 2020a; Olsson and Viscovi, 2020). Use and non-use are reported to be structured along the lines of social position. For example, groups of people who are older, have lower education and are less healthy are less likely to use digital technologies compared to their younger, well-educated and healthier counterparts (Fang et al., 2018; Hargittai, Piper and Morris, 2019; König, Seifert and Doh, 2018; Olsson, Samuelsson and Viscovi, 2017; Reiners et al., 2019; Seifert, Kamin and Lang, 2020). In such a divided context, digital technologies for accessing healthcare services can increase exclusion risks for those groups of older people with lower social positions who do not access and use digital technologies regularly (Czaja, 2017; Hargittai, 2018; Heart and Kalderon, 2013; Lutz, 2019; Olsson, Samuelsson and Viscovi, 2017).

Discussions around digital inequalities assume even more relevance in times of acceleration of digital transformation. The ongoing COVID-19 pandemic constitutes an exemplifying circumstance during which the use 


\section{Introduction}

of digital technologies has rapidly gained more importance in individuals' everyday lives than ever before (Khilnani, Schulz and Robinson, 2020). Due to social and physical distancing measures and the confinement of millions of individuals at home, the access to services of different kind, including healthcare, cannot always happen face-to-face and has become massively conditioned upon the use of digital technologies, such as teleconsultations, telemedicine, online bookings, electronic prescriptions (United Nations Fund for Population Activities, 2020; Watts, 2020). Those groups of older individuals who do not access and use digital technologies regularly have experienced reduced opportunities to fulfil their needs compared to their digitally savvy counterparts (Ayalon et al., 2020; Beaunoyer, Dupéré and Guitton, 2020; Reisdorf and Rhinesmith, 2020; Seifert, 2020; Seifert, Cotten and Xie, 2020; van Deursen, 2020).

This thesis takes a critical perspective on the incorporation of digital technologies in service provision and considers digital technologies as a contributing factor to growing risks of exclusion for some groups of older people and to widening social inequalities in old age. It is conducted from the perspective of ageing and social inequalities within the field of social gerontology ${ }^{1}$. Such a perspective provides the knowledge and the tools for approaching an investigation of what is behind an unequal participation of older people in a digital society. This work contributes to the ongoing discussions on ageing and technology, especially with regards to the understanding of mechanisms leading to digital inequalities among older people. The focus of the investigation is on those digital technologies which require individuals to actively use and interact with digital devices and necessitate digital competencies. Digital technologies and their features overall represent an important element, but the theoretical and conceptual focus of this thesis is neither on the technical aspects nor on the operating or application principles which are not touched upon in this work. Data materials for this thesis were collected in different countries in Europe (i.e. Germany, Italy, the Netherlands, Sweden) and concern two intervention studies evaluating two digital health technologies (i.e. an exergame technology for promoting physical activity among individuals with heart failure (the HF-Wii project) and a

1 This work has been conducted within the 'Supporting Self-Care by Information and Communication Technology (ICT) for Older People with Long-Term Conditions' (ICT4Self-care) research programme which was funded by the Swedish Research Council for Health, Working Life and Welfare (FORTE) (ref. 2014-4100). 
mobile-based communication system for post-surgical monitoring at home (the MIRAS project)) to reflect diversity. No comparative approach is taken.

\subsection{The Thesis Work}

Within this thesis, a mechanism that may drive digital inequalities among older people and which, in turn, reinforce social inequalities is studied. That mechanism is the unequal involvement of older people in research on digital technologies.

Some mechanisms leading to digital inequalities among older people are well known. For instance, people with lower social positions tend to have lower digital skills, to lack formal and informal support in using digital technologies, to face accessibility and affordability issues, and, therefore, are less likely to engage regularly with digital technologies compared to their counterparts. However, limited attention has been paid to research and development aspects and, among these, to the involvement of older people in research on digital technologies in influencing the participation of older people in a digital society. The understudied involvement of older people in research on digital technologies may further explain why some groups of older people are less likely to participate in a digital society compared to others.

Although targeted users are increasingly more often involved in key stages of research and development of digital technologies, some limitations have been identified, for instance, in relation to which stage they are involved in, the level of the user involvement, who is selected to be involved (Glasgow, 2007; Mannheim et al., 2019; Merkel and Kucharski, 2018). From the perspective of ageing and social inequalities, the most relevant issue concerns who is involved in the evaluations of digital technologies to represent the older people who are expected to be users of such technologies (Glasgow, 2007; Grates et al., 2018; Merkel and Kucharski, 2018).

Previous studies showed that health-related research, including digital health, often involves highly selected groups of individuals (Broendum et al., 2016; Mair et al., 2006). Compared to non-participants, participants are often younger, with higher levels of education and have a better health status (Broendum et al., 2016; Dodge et al., 2014; Foster et al., 2015; 


\section{Introduction}

Grates et al., 2018; Green et al., 2011; Mair et al., 2006; Westwood, 2017). The under-represented groups most likely include those who are less engaged with the use of digital technologies. A systematic exclusion of these groups from digital health research may bias results and misestimate effects of digital health technologies (Glasgow, 2007; Grates et al., 2018).

If participation of older people in the evaluations of digital health technologies is selective by social position, conclusions on digital health interventions are likely to be inaccurate and most likely even biased. Due to the under-representation of groups of older people who have lower social positions and are less likely to be digital users or experienced digital users, the measured outcomes can be an incorrect estimation of the effects on the targeted population. The outcomes may overemphasise the effects among groups of older people which are over-represented and mask the effects among the groups which are under-represented. Such inaccurate research outcomes reinforce digital inequalities and, in turn, social inequalities among older people, by poorly informing digitalisation policies and strategies on the utility of digital health among older people. For example, research outcomes could overestimate the effects of digital health and support an intervention that benefits only highly selected groups of older people, or could underestimate the effects of digital health and discourage an intervention that can be of support for those who had lower chances to participate in research.

\subsection{Aim and Research Questions}

This thesis aims at contributing to the understanding of mechanisms that drive digital inequalities among older people, by studying the involvement of older people in research on digital technologies. The overall objective of the thesis is to investigate the link between the involvement of older people in evaluations of digital technologies and research outcomes, taking digital health technologies as an example. 
Four main research questions guide the analyses and structure the presentations of results in the four analytical studies:

- How can selective participation of older people in research on digital health technologies be characterised and studied?

- Is participation of older people in evaluations of digital health technologies selective?

- What are the factors associated with participation of older people in digital health research?

- How can the effects of the selective participation of older people in digital health research on the research outcomes be described and corrected?

In Study I, participation of older people in research evaluating digital health technologies is conceptualised, and it is defined how selective participation could be studied and corrected. Also, a dedicated research tool for the study of self-selection is developed. Within Study II and Study III, factors which are associated with the participation in two intervention studies evaluating digital health technologies (i.e. exergame technology, mobile-based communication system) are analysed. In Study IV, the impact of selective participation on the research outcomes is measured and corrected in one of the two digital health intervention studies considered (i.e. mobile-based communication system).

Overall, this thesis gives answers on whether selective participation of older people in digital health research exists and has an inequality effect on the participation of older people in a digital society. It informs on who is less and who is more likely to participate in digital health research. It sheds lights on whether selective participation has an impact on research outcomes, and, depending on its impact, whether it masks unfavourable effects of digital health technologies for the under-represented groups of older people and, thus, whether it is a mechanism contributing to widening digital and social inequalities. 


\subsection{Expected Outcomes}

Findings from this thesis can lead to four possible outcome scenarios:

(a) Participation is not selective; no exclusion and inequality effects can be found. Participation of older people in the two evaluations of digital health technologies considered in this thesis (i.e. the HF-Wii project and the MIRAS project) is not selective. The likelihood of participating does not differ among older people. Research outcomes accurately reflect the targeted users. This indicates that digital health research generates accurate results and informs appropriate digitalisation strategies on the effects of digital health technologies among older people. Selective participation is not found and cannot be indicated as a mechanism leading to digital inequalities among older people.

(b) Participation is selective; no exclusion and inequality effects can be found. Older people in disadvantaged social positions (e.g. older, lower socio-economic status, poorer health) are less likely to participate in the two evaluations of digital health technologies considered for this thesis (i.e. the HF-Wii project and the MIRAS project). Participation is, thus, selective. Moreover, after conducting selective participation adjustments within the MIRAS project, research outcomes remain unchanged, i.e. the adjusted results do not differ depending on who participated and who did not. Therefore, although participation is selective, the outcomes obtained on the participants reflect the overall targeted older people well. This indicates that selective participation in digital health research does not have an exclusion and inequality effect among older people.

(c) Participation is selective; exclusion and inequality effects can be found. Older people in disadvantaged social positions (e.g. older, lower socio-economic status, poorer health) are less likely to participate in the two evaluations of digital health technologies considered for this thesis (i.e. the HF-Wii project and the MIRAS project). Participation is, thus, selective. Moreover, after performing selective participation adjustments within the MIRAS project, research outcomes show reduced positive effects. This suggests that groups of older people who were underrepresented in the evaluation would benefit less from the interventions than those who participated. The research outcomes mask the poorer effects of the intervention among the under-represented groups and 
overemphasise the effects among the over-represented groups. Such biased outcomes support digital health technologies which are suitable for some groups of older people but increase exclusion risks for groups of older people in disadvantaged social positions who are under-represented in research and less likely to use digital technologies. Most importantly, they inform wrongly political decisions on digitalisation strategies. Selective participation can, therefore, be a mechanism which contributes to widen digital and social inequalities.

(d) Participation is selective; a leveller effect can be found. Older people in disadvantaged social positions (e.g. older, lower socioeconomic status, poorer health) are less likely to participate in the two evaluations of digital health technologies considered for this thesis (i.e. the HF-Wii project and the MIRAS project). Participation is, thus, selective. Moreover, selective participation affects research outcomes. After performing selective participation adjustments within MIRAS, research outcomes show overall more positive intervention effects. This suggests that the groups of older people who were under-represented in the MIRAS intervention study would benefit more from the intervention compared with the groups who participated. Therefore, selective participation can mask more positive effects of digital health technologies among older people and prevent from showing that digital technologies can have a leveller effect among older people, allowing greater benefits for those groups of older people who have lower social positions and are less likely to use digital technologies.

\subsection{Structure of the Thesis}

Eight chapters compose this thesis. Chapter 1 - Introduction - describes the thesis context which consists of a society which is ageing, in which inequalities are steadily rising, and digital technologies are transforming the prerequisites for participating in society. The use of digital technologies is unequally distributed among older people. With digital technologies becoming more and more fundamental in individuals' everyday life, it becomes essential to identify and address those mechanisms which make some groups of older people more disadvantaged in a digital society. The involvement of older people in research is the mechanism conceptualised and studied within this thesis. Chapter 2, entitled Digital Society, presents an overview of how and to 


\section{Introduction}

what extent society is changing under the condition of rapid digitalisation. It describes policies, initiatives, and market strategies, that have been implemented at different levels for promoting a digital shift in several sectors, among which in service provision. The chapter sets the field of study for this thesis, that is the healthcare and healthcare provision. Chapter 3 - Ageing and Social Inequalities in Digital Societies - illustrates the key concepts and the theoretical framework of the thesis. It reviews dominant theories on social inequality and then explains why and how the perspective of the political economy of ageing appears to be the most appropriate theoretical framework for an investigation of inequality mechanisms in old age and, therefore, for this thesis. Chapter 4, titled Digital Technologies in the Healthcare Provision, describes opportunities and challenges brought by the advent of digital technologies in healthcare. It links this to digital inequalities and examines main factors associated with the non-use of digital technologies among older people and main mechanisms which enable lower social positions to predict a poorer digital engagement. Building on this, Chapter 5 - Evaluation of Digital Technologies as an Inequality Mechanism - presents a new possible mechanism explaining digital inequalities among older people, that is the involvement of older people in research on digital technologies. It reviews studies showing that some groups of older people are often less likely to participate in research, and that these groups often show disadvantaged social positions. It discusses the implications of a systematic under-representation of some groups of older people in research and, thus, in digital health research, for the accuracy of the research results, for the digitalisation strategies which are informed by the research, and for the reproduction of existing distributions of risks based on social locations. In Chapter 6 - Empirical Research, Materials and Methods - the reader may find information about the projects from which data were retrieved, a description of the research approach which drove the whole thesis investigation, details on the type of data which were used and statistical procedures which were employed for data analyses. Chapter 7 illustrates the results of this thesis work which are, then, discussed in Chapter 8. At the end of the book, the reader may find a copy of the four original publications produced in the context of this thesis. The survey instrument which was used for part of the data collection is available as part of the first publication. 
Arianna Poli 


\section{Chapter 2 \\ Digital Societies}

Since the first industrial revolution, a number of technological tools and relevant knowledge have cumulated, and this has led to the development of today's digital technologies. The beginning of the digital technology era is often dated as 1971, when the first microprocessor was released by the Intel company in California (Castells, 1996; Perez, 2009). This event initiated the microelectronics which drove the development of digital technologies as we know them today. Digital technologies is an umbrella term which refers to all those tools, such as smartphones, tablets, wearable devices, sensors, computers, that enable generating, storing, and processing data; they typically involve the use of internet and incorporate increasingly more often cutting-edge technologies, such as artificial intelligence (AI) (Lupton, 2014; Lutz, 2019; Tsertsidis, Kolkowska and Hedström, 2019).

Digital technologies contributed substantially to the progress of modern European societies. They have, for instance, improved distant communication, facilitated storage and spread of information, enhanced industry production, brought advances in medical diagnostics (Friedel, 2007; Headrick, 2009). Overall, the spread of digital technologies has 
occurred in various life domains and also affected the access and use of services.

\subsection{Digital Technologies in the Service Provision}

Service provision has changed because of the advent of digital technologies. Digital technologies are more and more used as means for delivering public services to citizens, such as those related to healthcare (Eccles, 2020; Holgersson and Söderström, 2019; United Nations, 2020). This trend has showed an acceleration in connection to the COVID-19 pandemic (United Nations, 2020; United Nations Fund for Population Activities, 2020). As a consequence of the preventive measures implemented to contain the spread of the virus, many services involving face-to-face interactions have been moved online, and new digital-based services have arisen (European Commission, 2020b; Scott et al., 2020; United Nations, 2020; United Nations Fund for Population Activities, 2020). Although this partly reflects emergency responses to the COVID19 crisis, many of these services are likely to stay and substitute some of the traditional services.

There is an overall expectation that the use of digital technologies for providing services will improve the current provision, by enabling quick, broad and flexible access and use of services by individuals (Eccles, 2020; European Commission, 2016, 2021b; Evangelista, Guerrieri and Meliciani, 2014; Helbig, Ramón Gil-García and Ferro, 2009; Murray et al., 2016; Schnoll, 2014; United Nations, 2020). In Europe, this is apparent, for example, in the large investments on digital infrastructures, digital industry and ad-hoc research programmes, in the dedicated legislations, in the digital inclusion initiatives, as well as in the implementation of specific monitoring tools for digital-related country performances (e.g. DESI) (Eccles, 2020; European Commission, 2016, 2020b, 2021b; OECD, 2016). During the 2014-2020 funding period, the European Commission earmarked over 20 billion euros to the European Regional Development Fund (ERDF) for supporting Information and Communication Technology (ICT) investments ${ }^{2}$. Research on ICTs received large support as well. Funding to research on ICTs has been growing by 25 per cent under the European Research and Innovation

\footnotetext{
${ }^{2}$ https://ec.europa.eu/regional_policy/en/policy/themes/ict/
} 


\section{Digital Societies}

Framework Programme Horizon 2020 (H2020) compared to the foregoing Framework Programme 7 (European Commission, 2019b). For the period 2021-2027, the European Union (EU) has announced that its support to key initiatives in the field of digital technologies will increase further, and has launched a funding programme, called the Digital Europe Programme, which is specifically dedicated to support a digital transformation in Europe (European Commission, 2021a). Moreover, several EU legislations have been approved in last few years for facilitating a digital shift in several spheres. For what concerns the healthcare sector, between 2014 and 2018, the EU legislated on key aspects, such as safety of medical devices, protection of personal data (General Data Protection Regulation - GDPR), trust of electronic identification, and security of network and information systems (European Commission, 2018; European Parliament, 2016). In addition to that, policy recommendations have been provided by the European Commission to the Member States since 2004 through dedicated policy documents called eHealth Action Plans. In 2012, the so-called eHealth Stakeholders Group was established with the role of developing new legislations and policies to guide a digital transformation in healthcare. The policy efforts expand also to digital inclusion initiatives. Digital inclusion policies range from the attempts to promote access to those who do not have access to devices, to user-centric policies encouraging key initiatives that create opportunities, mainly at community level, to engage with digital technologies and to develop digital skills. This includes, for example, equipping public libraries with more computers, providing free internet access in public areas, offering computer and internet training courses (Mariën and Prodnik, 2014). Although some of these initiatives were successful in increasing digital participation in absolute term, they were unsuccessful in making digital access and use more equal (Gallistl et al., 2020; Mariën and Prodnik, 2014; Thompson et al., 2014). Furthermore, specific monitoring tools were introduced to observe countries' digital performances both at European and international level. In 2015, the Digital Economy and Society Index (DESI) was released to supervise countries' progress with regards to, amongst others, digital skills, digital infrastructures, availability of digital services (European Commission, 2019a, 2020b). Also, Eurostat conducts an annual survey which focuses on ICT usage in households and by individuals in Europe. 
In parallel to this, the Information Technology (IT) market has been flourishing and invests more and more in digital solutions (Mazzucato, 2014). As a result of years of research and development, the knowledge in the field is increasingly more advanced, and a number of digital technologies are available on the market. As regards healthcare, it was estimated that the global market of digital health technologies would increase its value from 80 billion Euros in 2014 to 280 billion Euros by 2022 (Grand View Research, 2016). Europe is, together with the United States, one of the fast-growing markets in this respect. Just considering mHealth solutions, this market is projected to reach globally a value of 150 billion euros by 2025 (Deloitte Center for Health Solutions, 2015; Grand View Research, 2018).

The digital transformation of the service provision is progressing and promoted at different levels in Europe. Relevant research is supported, dedicated policies are defined, key legislations are approved, and the private sector is encouraged to invest and do so. Individuals are expected to adapt to the new ways of accessing and using services. Being willing and able to use digital technologies become a crucial prerequisite for having access to services and its resources.

\section{HEALTHCARE SERVICES}

In this thesis, healthcare is taken as example of a sector in which digital technologies are increasingly evaluated, promoted and used for providing services. Digital technologies in the healthcare domain go often under the name of digital health technologies, and the field of application is called digital health. Digital health incorporates also other terms like eHealth, mHealth, Connected Health (Lupton, 2014). Different types of digital technologies exist. This thesis will refer to those digital technologies that necessitate active engagement by the user and require some digital competencies to be used. Such technologies have been called direct enduser digital technologies in previous works (Weiss et al., 2018).

It is increasingly common that national healthcare systems offer services that comprise the use of digital health technologies, such as scheduling medical appointments on the web, consulting web portals for seeking health information and education, communicating remotely with the care providers (e.g. e-Prescription), accessing personal EHRs online, 


\section{Digital Societies}

using remote health monitoring (e.g. telemedicine, telehealth) (Barbabella et al., 2017; Bennett and Glasgow, 2009; European Commission, 2021b; Sixsmith, Mihailidis and Simeonov, 2017; World Health Organization, 2017). Digital health technologies complement or replace traditional face-to-face services (Kummervold et al., 2008), and they will likely cover a larger part of the healthcare offer in the near future (European Commission, 2018; United Nations, 2020; Weiss et al., 2018; World Health Organization, 2017).

As a result of the new trends in mortality and morbidity (Alley and Crimmins, 2010; Victor, 2010), the demand of healthcare for both acute and long-term care is rising and, along with that, the healthcare expenditures are increasing (de Meijer et al., 2013; European Commission, 2018; Lloyd, 2012; Tavares and Zantomio, 2017). Digital health is seen as a strategy for optimising the current healthcare provision by making it able to respond to the changing needs of the population, while reducing costs (European Commission, 2018; Heart and Kalderon, 2013; Ross et al., 2016; Weiss et al., 2018). However, the access and the use of digital technologies is unequally distributed, and this can constitute a challenge to digital health and digital society. 
Arianna Poli 


\section{Chapter 3 \\ Ageing and Social Inequality in Digital Societies}

\subsection{The Key Concepts}

This thesis work is developed around the connection that exists between ageing and social inequalities, in relation to digital technologies. Old age is unequal, and digital technologies are contributing factor to increased exclusion risks for some groups and growing inequalities in old age. Within a digital society, social inclusion and equality in old age depend also on the distribution of access and use of digital technologies among older people.

By investigating a mechanism which may contribute to explaining old age digital inequalities, this thesis addresses the connection between ageing, social inequalities, and digital technologies. The studied mechanism is the involvement of older people in research on digital technologies. The context used for this investigation is healthcare and the research on digital health technologies. Healthcare is used here as an exemplifying domain in which the use of digital technologies is becoming increasingly more important for accessing services and resources. 


\subsection{Social Inequality in Old Age}

Theories on ageing and social inequality can support the understanding of the mechanisms behind old-age digital inequalities. They explain how the divergence between groups of older people develops, by which factors, and which structural forces make some groups more likely to fall in the disadvantaged side of inequalities than others. The following sections outline some of the dominant theoretical contributions on social inequality in the field of social gerontology. A final section will elaborate on the application of the political economy of ageing as a main theoretical framework to this thesis.

\section{STRUCTURAL THEORIES ON AGEING AND SOCIAL INEQUALITY - A BRIEF OVERVIEW}

Theories on ageing and social inequality explain the nature of the unequal distributions of outcomes among older people. They elaborate on how inequalities work, and how outcomes get distributed by social position.

An important contribution to the theories on ageing and social inequality comes from the literature on ageing and social structure. This latter describes how individuals relate to the social structure and vice versa, and how they mutually regulate each other to maintain the existing social arrangements. Dominant concepts are agency within the structure (Settersten, 1999) and the duality of structure (Giddens, 2013; McMullin and Marshall, 1999). In a similar way, both concepts stress that individual outcomes reinforce the dominant social structure, and agency has little influence on this. Individual agency exists but is constrained by the social structure and, thus, does not generate significant deviations from expected outcomes (Marshall and Clarke, 2010).

Other theories on ageing and social inequality take a life-course perspective. These theories define how divergences between older individuals on life chances and outcomes are generated over time, consistent with the dominant social structure that predefines individual's and groups' trajectories. The most prevalent theory is the Cumulative Advantage/Disadvantage (CAD) theory (Dannefer, 2003, 2018). It is inspired by life-course theories (Bengtson, Elder Jr and Putney, 2012; Elder, Johnson and Crosnoe, 2003; Elder Jr, 1977) and theorises social 
inequalities as emerging from a generative process operating over individuals' lifetimes. As a result of this, early social statuses and achievements are responsible for the individual social locations and outcomes in later life.

According to the CAD theory, social inequalities in later life result from institutionalised cumulations of advantages and disadvantages over life. Such cumulation is not random but evolves systematically in a direction which is consistent with the dominant social structure. Common exemplifications for this are 'the rich get richer, the poor get poorer' or the Merton's 'Matthew effect' (Merton, 1968). The cumulation of advantages and disadvantages over life is 'the systemic tendency for interindividual divergence in a given characteristic (e.g. money, health, or status) with the passage of time' (Dannefer, 1987). As a systemic tendency, $\mathrm{CAD}$ originates from a process which is inherently characteristic of social systems. It results from the stratifying effect of a complex set of social systems or institutions that operates during the life course to delineate certain individual life trajectories. Individual differences are, thus, the products of social processes (Dannefer, 2018). For example, education stratifies individuals earlier in life with effects in later life when inequalities exacerbate based on factors associated with educational levels. This determines a continuous interindividual divergence of availability of life chances, achievement of outcomes, and exposure to risks that follows the dominant social structure, namely social inequalities.

Building on the CAD theory, Ferraro and colleagues developed the cumulative inequalities (CI) theory (Ferraro, Shippee and Schafer, 2009). Similar to the CAD theory, CI explains how social inequalities and inequality positions are created and maintained. Social inequalities are structurally generated over time, and the social locations of individuals result from 'accumulation of risks, available resources, perceived trajectory, human agency' (Ferraro, Shippee and Schafer, 2009). The directions of life trajectories are modifiable by resource mobilisation and human agency but are largely pre-determined by individual social positions.

Not only early status and life achievements determine different experiences of old age for different groups of individuals, but also major reorganisations in society. Recent works suggested that vulnerability in 
later life originates from cumulated disadvantages over life and is reinforced and sustained by changes in the social systems that reduce protection, for example, in the context of political austerity (Grenier and Phillipson, 2018; Grenier and Phillipson, 2020; Grenier et al., 2017). This conceptualisation goes under the name of old age precarity and aims at complementing the previous theorisations on social inequalities in old age (Grenier and Phillipson, 2020; Grenier et al., 2017). This concept has recently stimulated criticisms. According to some scholars, inequalities in later life primarily result from structural mechanisms operating over the life course of individuals, and there is not yet sufficient evidence that they are aggravated by restructured social systems (Gilleard and Higgs, 2020).

Overall, theories based on the cumulation of advantages and disadvantages over a lifetime are dominant theories on social inequality in social gerontology. The main contribution of these theories has been to point to the generative process at the basis of social inequality in old age. However, they focus less on the mechanisms which determine certain distributions of outcomes in old age. In this respect, the political economy of ageing has the study of the mechanisms reinforcing inequalities at its core. The political economy of ageing details how institutional forces make an impact on the individuals and make older people structurally disadvantaged compared to other age groups, and how some groups of older people achieve systematically poorer outcomes than others.

\section{SOCIAL INEQUALITY AND THE POLITICAL ECONOMY OF AGEING}

Social inequality is at the heart of the political economy of ageing (Phillipson and Baars, 2007; Quadagno and Reid, 1999; Walker and Foster, 2014). The political economy of ageing emerged in the ' $80 \mathrm{~s}$ in contraposition to the functionalistic views on ageing which considered conditions such as marginalisation, dependency, and poverty as inevitable consequences of growing old, and chronological age as a main predictor for them (Walker and Foster, 2014). In opposition to such view, the political economy of ageing introduced the idea that ageing is instead socially constructed, as well as the conditions an older person lives in, such as being retired, dependency, exclusion (Townsend, 1981; Walker, 
1980). These conditions and the individual experiences of old age tend to reiterate and reinforce the prevailing social structure and to reflect the political culture within a society (Foster, 2012).

From the perspective of the political economy of ageing, old age results from a combination of forces working at societal (macro), institutional (meso), and individual (micro) levels (Estes, 2001). Economic and political processes stimulate policies which influence the individual experience of old age (Estes, 2001). Such experience of old age reflects the dominant social structure and varies along the lines of aspects such as education, income, gender (Estes, 2001). Social inequalities must be traced back to macro processes and the policies which follow (Quadagno and Reid, 1999). This latter defines certain allocations of resources which impact different groups of older people differently depending on aspects which characterise their social position, such as education, income, gender (also known as the interlocking systems of inequality (Minkler and Estes, 2019)). Such differential impacts are sustained by inequality mechanisms which operate by disadvantaging groups in disadvantaged social positions over their counterparts (Estes, 2001; Walker and Foster, 2014). Understanding such mechanisms allows interventions for mitigation of inequalities.

By explaining the structural nature of disadvantaged experiences of old age, the political economy of ageing seems to be particularly appropriate for the study of old age digital and social inequalities in this thesis. Indeed, the focus of this work is not on the mechanism of interindividual divergences over the life-course and, thus, CAD and CI theories are not fully sufficient here. Rather, it is the interest of this thesis to expand the knowledge on mechanisms leading to digital inequality which make groups of older people diverging one another by social position on their participation in a digital society.

However, the political economy of ageing in its original macro approach also shows some limitations with regards to this thesis. Such approach mainly describes how institutional forces lead to disadvantages for older people compared with other age groups (i.e. social inequality between age groups) but puts less emphasis on social inequality among older people and provides limited insights on processes of its generation. Hence, this thesis uses an extended perspective of the political economy of ageing, as described for example in Estes' work (2001) and in Walker's 
re-examination (Walker, 2016). This extended perspective comprises the idea of a differential effect of policies among older individuals, depending on aspects like social class, gender, sustained by inequality mechanisms. In this view, policies lead to an unequal distribution of outcomes which disadvantages some groups of older people more than others. In this latter formulation, the political economy of ageing appears to be particularly helpful for investigating the mechanisms which link individual social position and participation in a digital society.

\subsection{The Mechanism of Selective Participation in Research on Digital Technologies}

The mechanism which is studied in this thesis is the selective participation of older people in research on digital technologies. Previous research suggested that participants and non-participants in research on digital technologies are different one another, with the latter having more often lower social positions (Broendum et al., 2016; Dodge et al., 2014; Foster et al., 2015; Green et al., 2011; Mair et al., 2006). Selective participation in research on digital technologies may work as a filter which prevents groups of older people with lower social positions and lower digital familiarity from influencing research outcomes by underrepresenting them in the research. The under-representation of these groups and the over-representation of their counterparts can generate research outcomes which are an underestimation or an overestimation of the actual effects. This leads to inaccurate conclusions and poorly inform political decisions on digitalisation which can reinforce existing disadvantages and unequal participation in a digital society. Selective participation of older people in research may contribute to explain why participation in a digital society varies between groups of older people by social position, i.e. digital inequalities. 


\section{Chapter 4 \\ Digital Technologies between Potential and Inequalities}

\subsection{Potential of Digital Technologies in Healthcare}

Much research has been conducted to investigate the utility of using digital technologies in the healthcare provision of services (Bennett and Glasgow, 2009; Boise et al., 2013; Eccles, 2020). At an individual level, studies have explored whether delivering healthcare services by the use of digital technologies is effective and well-received by users and ensures good standards of care. At an organisational level, research has been mostly investigating the impact on care-load and costs.

The use of digital health technologies can impact positively on individual physical (Gellis et al., 2012; Jaarsma, 2020; Yun et al., 2018) and mental outcomes (Cotten et al., 2014; Forsman et al., 2017), increase perceived health status and enhance self-care behaviours (Bhattarai and Phillips, 2017; Franklin, Lavie and Arena, 2015), sustain quality of life (QOL) and well-being (Khosravi and Ghapanchi, 2016; Nimrod, 2019; Siegel and Dorner, 2017; Sims, Reed and Carr, 2016), reduce social 
isolation and loneliness (Chen and Schulz, 2016; Cotten et al., 2014; Yu, $\mathrm{Wu}$ and Chi, 2020). Positive impacts have been identified at an organisational level, too. The integration of digital health technologies into the healthcare service delivery can delay, shorten, and reduce hospital admissions (Ding et al., 2020; Kitsiou et al., 2017; Lloyd, 2012), decrease the uptake of face-to-face healthcare services (Carretero, Stewart and Centeno, 2015), generate cost-efficiency (Boodoo et al., 2020; Chen and Chan, 2013; Jiang, Ming and You, 2019), as well as support integrated care (Barbabella et al., 2017; Melchiorre et al., 2017).

Overall, evidence from research evaluating digital technologies supports a digital shift in healthcare; however, there are studies stressing that the positive impact of digital technologies mostly occurs for specific groups of users and in specific contexts (Damant et al., 2017; Eccles, 2020; Gallistl and Nimrod, 2019). The potential of digital health technologies is challenged by digital inequalities.

\subsection{Challenges through Digital Health Technologies}

\section{DIGITAL INEQUALITIES}

The access and the use of digital technologies is unequally distributed among individuals. This is digital inequalities. The first studies on the unequal access to digital technologies emerged in the early ' 90 s, mostly in connection to the diffusion of internet and computers. Although internet and computers were available only to limited groups of people at that time, scholars noted that the spread of digital technologies was following an unusual pattern of diffusion compared to previous technological and communication means (Anderson, 1995). Unlike the radio and the television for which the adoption steadily increased until full penetration, digital technologies diffused rapidly among specific groups in the population but then slowed down before reaching a large audience (DiMaggio et al., 2004).

The research on digital access and digital use has advanced much in the past two decades and produced important conceptualisations which allowed for the systematisation of the study of exclusion and inequalities in a digital world (Berkowsky and Czaja, 2018; Francis et al., 2019). The term digital divide was introduced to describe the gap between those 
individuals who have access to internet and other digital means and those who do not, namely the contraposition between haves VS have nots. (Francis et al., 2019; Friemel, 2016; van Dijk and Hacker, 2003; Yu et $a l ., 2016)$. Over time, the concept of digital divide has been further elaborated to keep up with the growing complexity of participation and non-participation in a digital world. The early conceptualisation of digital divide went under the new name first-level digital divide and further divide levels were added - a second-level and a third-level digital divide. The second-level digital divide refers to the fact that people differ greatly with regards to their levels of digital skills and, thus, use digital means in different ways. Such types of use can be more or less effective and lead to different degrees of returns (Hargittai, 2002; Hargittai, Piper and Morris, 2018). The third-level digital divide focuses on the distribution of tangible outcomes which derive from the use of digital means. It highlights that returns from access and use of digital technologies are greater for some individuals than for others (A. J. Van Deursen and E. J. Helsper, 2015). Such returns tend to influence offline outcomes too, such as economic (e.g. accessing better jobs, buying cheaper services and goods), social (e.g. more opportunities to cultivate social networks), political (e.g. broadening civic and political engagement), institutional (e.g. easier access to public institutions), and educational (e.g. more opportunities to obtain training, having access to a broader range of information) (A. J. Van Deursen and E. J. Helsper, 2015).

The concept of digital divide is closely related to the concept of digital inequalities. The unequal distribution of access and use of digital technologies implies that some groups of people have better chances than others to use and access digital technologies and to reach better outcomes than others (DiMaggio and Garip, 2012; Halford and Savage, 2010; Lupton, 2016; Robinson et al., 2015; Weiss et al., 2018). Not everyone experiences the advantages of living in a digital society, and digital inequalities tend to follow existing social inequalities (Lutz, 2019; Mariën and Prodnik, 2014; Robinson et al., 2015). Those groups who have disadvantaged social positions fall most likely in the disadvantaged side of the digital inequalities, experiencing lack of access, skills, poorer or no returns from digital technology use and access. 


\section{DIGITAL INEQUALITIES IN OLD AGE}

Digital inequalities in old age especially challenge the use of digital technologies in healthcare provision. Older people represent one of the main user groups of healthcare services (Eccles, 2020; Gulliford and Alageel, 2019; Pirhonen et al., 2020; Terraneo, 2015) and, at the same time, are less likely to use digital technologies (Eurostat, 2021; König, Seifert and Doh, 2018; Seifert, Cotten and Xie, 2020). Eurostat data from 2020 report that 32 percent of the individuals 65-74 years old has never used internet; data on computer use from 2017 (the latest data available on the use of computers) show that 44 percent of the individuals 65-74 years old has never used a computer (Eurostat, 2021). Most importantly, the use of digital technologies among older people is unequally distributed. Some groups of older people do not use digital technologies or use digital technologies significantly less or more poorly than others and are therefore excluded from a digital society (Eurostat, 2017; König, Seifert and Doh, 2018; Olsson, Samuelsson and Viscovi, 2017; Olsson and Viscovi, 2020; Pirhonen et al., 2020). Several studies investigated factors associated with non-use and low use of digital technologies among older people and described mechanisms which enable poor digital engagement by some groups of older people. An overview is provided in the sections below.

\section{SOCIO-STRUCTURAL FACTORS: INDIVIDUAL LEVEL}

Individual characteristics, such as education, income, age, living area, and health, are associated with participation of older people in a digital society.

Several studies found an association between level of education and income, and the use of digital technologies among older people. Older people with a higher level of education and higher income are more likely to be digitally engaged compared to their counterparts (Bol, Helberger and Weert, 2018; Calhoun and Lee, 2019; Friemel, 2016; Hunsaker and Hargittai, 2018; Macdonald and Hülür, 2020; A. van Deursen and E. J. Helsper, 2015; Yu et al., 2016). Prior experiences with using digital technologies at work also play a role in this. In that respect, having used a computer or other digital devices at work is associated with being a user of digital technologies in later life (Friemel, 2016; Konig, Seifert and 
Doh, 2018). Age has been recognised as a predictor of digital use, namely younger-old people are more likely to use technologies than the older ones (Bol, Helberger and Weert, 2018; König, Seifert and Doh, 2018; Macdonald and Hülür, 2020; Mitzner et al., 2016; Silva, Matos and Martinez-Pecino, 2017). Age was also found to be associated with the level of digital skills. Younger-old individuals are more likely to have higher digital skills than the older counterpart (Hunsaker and Hargittai, 2018). The influence of gender is less clear. Although some studies found that male are more likely to be digital users (König, Seifert and Doh, 2018; Matthews, Nazroo and Marshall, 2019; van Deursen and van Dijk, 2011), others reported no differences (Friemel, 2016; Silva, Matos and Martinez-Pecino, 2017). The online behaviours seem to vary between older men and women (Bol, Helberger and Weert, 2018). For instance, women tend to engage online for communication and informal interactions more than men do, but men perform a wider range of activities online (Robinson et al., 2015).

Marital status, co-habiting, and living areas are also associated with being or not being a digital user. In particular, having a partner, living with someone else, and having intergenerational relationships (e.g. with children, grandchildren) increase the adoption of digital technologies by older people (Freeman et al., 2020; Friemel, 2016; Macdonald and Hülür, 2020; Neves, Amaro and Fonseca, 2013; Vroman, Arthanat and Lysack, 2015). Moreover, the living area predicts older people's digital use. Older people living in rural or remote areas are less likely to use digital technologies compared to those living in urban areas (Berner et al., 2014; Hong and Cho, 2016).

Many studies identified health status as a predictor of use of digital technologies. Previous studies showed that poorer health decreases the use of digital technologies (Gell et al., 2015; Hargittai, Piper and Morris, 2018; Heart and Kalderon, 2013; Hunsaker and Hargittai, 2018; Keränen et al., 2017; Levine, Lipsitz and Linder, 2016; Matthews, Nazroo and Marshall, 2019). Similar association was found between poorer cognitive health and use of digital technologies (Calhoun and Lee, 2019; Hedman et al., 2015; Macdonald and Hülür, 2020; Schmidt and Wahl, 2018). 
Contextual factors are also associated with the use of digital technologies in old age. König and colleagues found that older people's use of internet varies also depending on the wealth of the country of residence, measured as gross domestic product (GDP) (König, Seifert and Doh, 2018), namely the wealthier the country the higher the digital engagement among older people. Furthermore, availability of the necessary infrastructures in the country and in the living area (e.g. rural/urban), as well as affordable prices for broadband and devices, increase the use (Guillén and Suárez, 2005; König, Seifert and Doh, 2018). In addition to the economic context, political decisions are relevant in supporting the use of technologies among older people. Prioritising initiatives for improving telecommunication infrastructures and increasing digital inclusion of those who are less digitally engaged, increases the use of digital technologies among older people (Cotten, Anderson and McCullough, 2013; Silva, Matos and Martinez-Pecino, 2017).

\section{SOME EXAMPLES OF MECHANISMS}

Several mechanisms are known that link structural factors to older people's participation in a digital society. For instance, older people with disadvantaged social positions are more likely to have developed lower digital skills and to report lower confidence with using digital technologies (Olsson, Samuelsson and Viscovi, 2017; Robinson et al., 2015). Also, they have more often poorer access to digital devices and lack the support for using and learning how to use digital technologies (Coughlin, 2020; Friemel, 2016; Hargittai, Piper and Morris, 2019; Mitzner et al., 2018; Tsai et al., 2015; Wilson et al., 2021). By this, older people with disadvantaged social positions perform more limited range of activities through digital technologies, get discouraged when encountering technical issues, feel uncomfortable when required to provide personal information on the web, struggle with technical terms which happen to be more often in English, and are less often regular users (Allemann and Poli, 2020; Fischl et al., 2020; Hargittai and Dobransky, 2017; Hargittai, Piper and Morris, 2018). 


\section{FINAL REMARKS}

This brief overview of the literature is aimed at summarising main sociostructural factors and mechanisms that are associated with non-use and poorer use of digital technologies and at showing the complexity of digital participation among older people. However, more mechanisms leading to digital inequalities in old age exist.

Recently, scholars have brought the attention towards aspects which are related to research and development of digital technologies and can contribute to the exclusion of older people from participation in a digital society (Czaja, 2017; Grates et al., 2018; Merkel and Kucharski, 2018). The next chapter addresses especially one of these aspects, that is the involvement of older people in research evaluating digital technologies. This latter may be a mechanism that contributes to explain why groups of older people with disadvantaged social positions fall into the disadvantaged side of digital inequalities. 
Arianna Poli 


\section{Chapter 5}

\section{Evaluation of Digital Technologies as an Inequality Mechanism}

Scholars have recently emphasised that there are aspects of research and development of digital technologies which can account for digital inequalities, namely for why some groups of older people are less likely to use and access digital technologies (Czaja et al., 2019; Grates et al., 2018; Merkel and Kucharski, 2018). Some of them are design-related. It is stated that the design of a digital technology is often based on limited inputs from the targeted users and therefore can respond better to the needs and the preferences of some groups of older individuals and less those of others (Allemann and Poli, 2020; Czaja et al., 2019). Other mechanisms relate to knowledge translation of research and development outputs. Studies reported, for instance, that scientific evidence is not always accurately translated into practice. This compromises the ability of an innovative intervention or service to address the needs of targeted older people (Glasgow and Chambers, 2012). Other studies found that the implementation of digital health technologies does not always consider the outcomes of evaluations or is not preceded by an evaluation (Ossebaard et al., 2012; van Gemert-Pijnen et al., 2011).

From an inequality perspective, the involvement of older people in research evaluating digital technologies is most interesting. Research 
findings and conclusions are likely to differ, depending on which groups of older people are involved (Grates et al., 2018; Merkel and Kucharski, 2018). If participation is selective, outcomes for those groups who are less likely to be involved can be masked by the outcomes of the groups who are more likely to be involved. This prevents identifying how different groups react to the same intervention, and how intervention outcomes may actually be distributed in the target population.

\subsection{Involving Older People in Research and Development of Digital Technologies}

Before coming into use in service provision, digital technologies go through a series of stages which typically involve targeted users and includes activities like ideas development, design, evaluation, implementation (Ghulam Sarwar Shah and Robinson, 2006; Shah, Robinson and AlShawi, 2009).

The involvement of users in research and development of digital technologies can take different forms and vary in its extent. The involvement ranges from no involvement at all, in which the needs and the interests of target people are mostly assumed, for example, based on the literature or on a persona, to a full involvement, in which users are involved in all the stages from ideas development to implementation and have an influence along the whole process (Beresford, 2013; Merkel and Kucharski, 2018; Panek et al., 2017).

\section{EVALUATIONS OF DIGITAL TECHNOLOGIES}

Among the different activities related to research and development of digital technologies, older people most often participate in evaluations (e.g. intervention studies, pilot studies) (Merkel and Kucharski, 2018).

Evaluations measure and anticipate all the possible impacts of a given digital technology on the chosen target population, for example in terms of health status, well-being, and acceptance. In order to do so, it is crucial to involve future users who reflect the targeted population well enough to capture the heterogeneity of needs, interests and preferences which may lead to differential outcomes (Czaja et al., 2019; DeSmet et al., 2016; Glasgow, 2007; Grates et al., 2018; Merkel and Kucharski, 2018). 
Whether or not the target population of interest is well reflected in the group of study participants is defined along the recruitment process.

\subsection{Selective Participation}

The group of study participants is a sample which is drawn from the target population of interest at a given recruitment site. Within the targeted group at the recruitment site, some people are screened and deemed eligible to participate, and others are excluded. Some people accept the invitation to participate, and others decline. The likelihood of being screened, eligible, and accepting to participate should ideally be similar for everyone belonging to the target population of interest. However, this is not always the case.

Older people participating in evaluations of digital health technologies often do not fully reflect the population which is meant to be recipient of the intervention (Glasgow, 2007; Grates et al., 2018; Merkel and Kucharski, 2018). Those who participate are typically younger, with better health status, higher digital skills, and in better socio-economic conditions than those who do not participate (Broendum et al., 2016; Dodge et al., 2014; Foster et al., 2015; Green et al., 2011; Mair et al., 2006). As the likelihood to participate is not equally distributed among individuals in the target population, the recruitment processes produce biased groups of study participants which are dissimilar from the target populations of interest. The under-representation of some groups of older people and the over-representation of others hinder the ability of evaluations to test the hypothesised effects and find the actual impacts of an intervention in the target population.

In this thesis, participation in research is described as originating from three processes which occur along the recruitment of study participants, namely pre-screening, recruitment, and self-selection. In the prescreening, some individuals identified as target at a recruitment site are not considered for screening; the exclusion of them happens before any proper eligibility check for participation in the study. In the recruitment, individuals are screened for eligibility criteria and deemed eligible or ineligible, accordingly. In the self-selection, eligible individuals decide whether they want to be study participants or decline the study invitation. The three processes work independently but lead together to a four-group 


\section{Arianna Poli}

structure: a non-screened group (which was excluded prior screening), a non-recruited group (which was screened, but found to be ineligible), a decliner group (which was screened, recruited but declined to participate), and a participant group (which was screened, recruited, and decided to participate) (Figure 1).

In the following sections, literature on non-participation in healthrelated research, including digital health research, is presented and structured in the three processes: pre-screening, recruitment, and selfselection. Some of the reported studies specifically targeted older people, while other studies focused on broader groups.

Figure 1. Processes behind selective participation along the recruitment of study participants

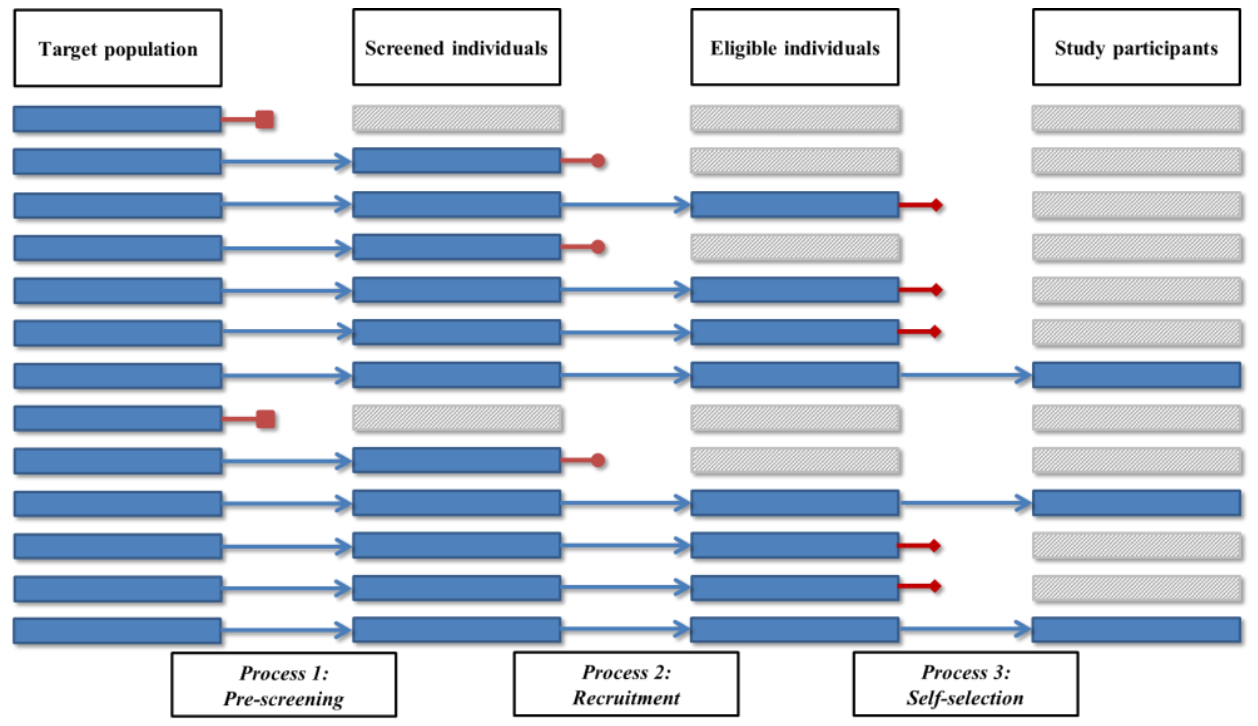

Source: Adapted from Poli et al. (2019); Poli et al. (2021) (under review).

\section{PRE-SCREENING AND RECRUITMENT}

Pre-screening and recruitment are the first two processes in which the inclusion or the exclusion of individuals from participating in the research are defined. 
The pre-screening precedes the phase in which individuals are checked for eligibility criteria to the intervention study. Although no studies have been found which describe such process, it is assumed that some people may be screened out before a formal eligibility check, with no formal documentation of reasons for such exclusion. This may happen, for example, due to absence of some individuals at the time of the screening, absence of the recruiter, assumed ineligibility of some individuals by the recruiter. This creates a discrepancy between the targeted groups of individuals at the recruitment site and the groups of individuals who actually undergo the formal eligibility check for participating in intervention studies.

The recruitment involves all the individuals who passed the prescreening process. The recruitment is the step in which individuals are screened to check if they conform or not with the inclusion/exclusion criteria of the intervention study. Those who are suitable to the intervention study stay in the recruitment process, while those who are not suitable are excluded.

Only few studies investigated the recruitment processes from a perspective of selective involvement of different groups of older people. These studies showed that very old people, people with hearing and sight impairments, people with cognitive impairments and dementia, people with multiple comorbidities, and people who are deemed by the recruiters to be more likely to drop-out from the intervention study, are more often excluded at the stage of recruitment (Bourgeois et al., 2016; Britton et al., 1999; Cherubini et al., 2011; Domingos et al., 2015; Taylor et al., 2012; Thake and Lowry, 2017).

\section{SELF-SELECTION}

Self-selection is the third process contributing to selective participation. People who underwent the screening and are deemed eligible for the intervention study are invited to participate. The self-selection process refers to the individual decision of accepting or declining the invitation to participate in the intervention study. Self-selection distinguishes between older people who decline and older people who participate in the intervention study (Figure 1). 
Previous studies investigated factors associated with individual unwillingness to participate in health-related research, including digital health, and analysed reasons for declining. Factors seem to fall mainly into the following areas: socio-demographic characteristics, health status and quality of life (QOL), social participation, and social network. As regards the reasons, issues related to time resources, transportation barriers, lack of interest, and technology use, are the most common reasons for declining.

\section{FACTORS ASSOCIATED WITH SELF-SELECTION}

\section{Socio-demographic Characteristics}

Socio-demographic characteristics are associated with the likelihood to participate in health-related research. Previous studies indicated that age predicts the willingness to participate in health-related research; research participants are generally younger than those who refuse to participate (Broendum et al., 2016; Flink, Brandberg and Ekstedt, 2019; Jordan M. Harrison et al., 2016; Mair et al., 2006; Michelet, Lund and Sveen, 2014; van Heuvelen et al., 2005). The effect of gender on the willingness to participate is less clear. Although some studies reported that men were more likely to consent to participate than women (Broendum et al., 2016; Creel et al., 2005; Green et al., 2011; Lloyd-Williams et al., 2003; Williams et al., 2007), other evidence describes the opposite effect (Yang et al., 2017) or no gender effect on participation (Jordan M. Harrison et al., 2016).

Decliners report more often lower level of education compared to study participants (Gaertner et al., 2016; Green et al., 2011; van Heuvelen et al., 2005). It is less clear whether having a partner or living together with someone has an impact on the willingness to participate among older people. In a trial testing a self-management intervention, older people who declined the invitation to participate were more likely to have a partner than those people who agreed on participating (Elzen et al., 2008); opposite effect was found in another study (Gollhofer et al., 2015). 


\section{Health Status and QOL}

People who decline to participate differ from those who participate in health-related research by health status and QOL. Studies found that, compared to study participants, decliners are more likely to show poorer health status (Elskamp et al., 2012; Gollhofer et al., 2015; Provencher et al., 2014; van Heuvelen et al., 2005), report cognitive impairments (Chatfield, Brayne and Matthews, 2005), and indicate lower QOL (Gaertner et al., 2016).

\section{Social Support and Participation}

In an intervention study promoting physical activity among older people, participants reported lower social support compared to decliners (van Heuvelen et al., 2005). Similarly, other studies found that participants reported higher need of support compared to decliners (Flink, Brandberg and Ekstedt, 2019; Foster et al., 2015). In other studies, study participants reported to enjoy engaging in activities that could contribute to science and help other people and society (Bongartz et al., 2017; Coley et al., 2018).

\section{Time Resources}

Lack of time and competing tasks are common reasons for declining to participate (Akmatov et al., 2017; Elzen et al., 2008; Foster et al., 2015; Gollhofer et al., 2015; Jordan M. Harrison et al., 2016; Normansell et al., 2016; Palmas et al., 2006). In some cases, not having time was due to own care-related activities (Flink, Brandberg and Ekstedt, 2019).

\section{Access and Use of Digital Technology}

When the invitation concerns the participation in an intervention study evaluating digital technologies, reasons for not participating are often related to digital use and access. For example, low perceived usefulness of digital health technologies (Palmas et al., 2006; Subramanian et al., 2004), lack of access to the internet and computer (Foster et al., 2015), are commonly reported among decliners. 


\section{Other Reasons}

Further reasons for declining to participate comprise logistic barriers (Chang et al., 2004; Elskamp et al., 2012; Jordan M. Harrison et al., 2016; Karlawish et al., 2008), no interest in the research (Broendum et al., 2016; Chang et al., 2004; Foster et al., 2015; Jordan M Harrison et al., 2016; Palmas et al., 2006), being ill (Chatfield, Brayne and Matthews, 2005; Flink, Brandberg and Ekstedt, 2019; Jordan M Harrison et al., 2016). Some individuals refuse to participate as they are satisfied with the existing care services and not interested in testing new ones (Elskamp et al., 2012; Sanders et al., 2012; Subramanian et al., 2004).

\section{REMARKS}

In sum, literature indicates that study participants and non-participants can differ one another. Participants tend to be younger, with better health status, with higher level of education (Foster et al., 2015; Green et al., 2011). However, some important research gaps on selective participation in research can also be found.

Overall, little attention has been paid to selective participation of older people in research on digital technologies. Many of the existing studies focused on broader populations than older people and on participation in medical- or health-related research with no connection to digital technologies. A proper conceptualisation of selective participation in research is missing, and its study has not been systematic. The existing literature does not define how selective participation should be studied, and limited attention has been concentrated on defining what selection processes generate a selective participation, and how these selection processes are ordered and related one another. The processes of prescreening and recruitment have been under-investigated. Much of the existing literature addressed participation by focusing on the process of self-selection only.

In order to understand the involvement of older people in research on digital technologies, a conceptualisation of selective participation in research on digital technologies and a systematisation of its study are needed. The starting point for such conceptualisation has to be the identification of the processes of selection, of their succession, and of their reciprocal links. This allows a systematic study of selective 
participation of older people in research on digital technologies, which can clarify what are the factors associated with each of the processes of selection, when is non-participation due to study requirements or to individual decisions, what is the impact of pre-screening, recruitment, and self-selection on the research outcomes, and what can be done for solving such impact.

\subsection{Selective Participation as a Methodological Problem}

Selective participation in research relates to issues that have been traditionally studied within the fields of research methodology and epidemiology, such as non-response and representativity.

Within the field of research methodology, selective participation is mostly discussed in connection to non-response in survey studies. Nonresponse can be generally defined as the lack of success in collecting data from a large percentage of people in the target population (Fowler Jr, 2013) and can in some cases be source of error in the results. Nonresponse does not represent necessarily a source of error for the study results (Hendra and Hill, 2019; Kohut et al., 2012), unless it leads to a sample which is too much different from the target population (Fowler $\mathrm{Jr}, 2013)$. The goal of a survey study is typically to provide estimates for the characteristics of a certain population of interest based on the information collected on a sample which is drawn from the target population. The fundamental assumption is that the estimates obtained on a sample are accurate for describing the population to which the sample belongs. In order for this assumption to hold true, the characteristics of the individuals in the sample are to be distributed in the same (or similar) way as in the target population. If the chances of responding are distributed unevenly among individuals in the target population, such similarity between the sample and the target population is reduced, with possible implications for the estimates.

When non-response involves some specific groups of individuals from the target population, the obtained estimates are likely to be applicable only to that part of the target population that had chance to respond to the survey study. Nevertheless, evidence about the impact of non-response on estimates are controversial in the literature. On the one hand, some studies indicated that selective non-response reduces the estimate ability 
to describe the target population (for example, (Harvey et al., 2018; Kelfve, 2019; Knudsen et al., 2010). The magnitude of the error in the estimates depends on the extent to which the non-response is related to the estimates (Fowler Jr, 2013; Kelfve, Thorslund and Lennartsson, 2013). For example, people interested in the use of new technologies may be more likely than their counterpart to participate in an evaluation of a digital-based intervention. In this case, the individual interest in the use of new technologies could lead to a modification of the results of the intervention as participants can presumably be more engaged and confident with the use of the intervention compared to those who were not interested in the use of technologies and choose not to participate. On the other hand, other studies reported little or no impact of non-response on estimates (Søgaard et al., 2004; Van Loon et al., 2003).

Selective participation in research also relates to the ongoing discussion around the relevance of representativeness in studies. For long time now, epidemiologists have been discussing whether and when representativeness is necessary in studies but did not reach a consensus so far. According to some scholars, representativeness is usually not necessary (Richiardi, Pizzi and Pearce, 2013; Rothman, Hatch and Gallacher, 2014). Main arguments for this can be summarised as follow. First, the biases which can be introduced based on the selection process are modest and thus negligible (Richiardi, Pizzi and Pearce, 2013) and, second, results obtained from representative populations describe an average effect for the population which is less informative than the effects on specific subgroups (Rothman, Gallacher and Hatch, 2013). On the other hand, other scholars believe representativeness should not be avoided a priori. They emphasise the importance of representativeness especially when research results need to inform welfare planning and policy, and advice to assess carefully the need for representativeness in each study (Ebrahim and Davey Smith, 2013). Non-representative samples can generate potential false conclusions especially when specific groups in the population are systematically omitted, or when factors which are associated with the investigated outcomes are also associated with the probability for an individual of being selected (Ebrahim and Davey Smith, 2013).

In the context of this thesis, the representativity issue as it has been discussed within the field of epidemiology is informative but only partly relevant. The focus of this thesis is less on the issue of representing the 
whole population but rather on the importance of reflecting the diversity of a specific target population, located in a given recruitment site and in a given time, in the study samples. The literature on non-response helps to understand the impact of selective participation on sample composition and research results, but it interprets insufficiently the processes leading to selective participation. 
Arianna Poli 


\section{Chapter 6}

\section{Empirical Research, Materials, and Methods}

This dissertation comprises four publications. Each of them contributes to the overall investigation of the link between the involvement of older people in research on digital health technologies and the research outcomes (Figure 2).

In Study I, participation of older people in research is conceptualised, and it is defined how selective participation could be studied, measured, and corrected. Also, the NPART (Evaluation of Non-Participation in Digital Health Research) research tool for the study of self-selection in digital health research is developed and piloted. In Study II and III, selective participation is examined in two intervention studies evaluating digital health technologies, identifying a) which groups of older people are less or more likely to take part in digital health research, and b) what predicts participation. In Study IV, the impact of selective participation on the research outcomes is identified and corrected in one of the two digital health intervention studies considered. 
Figure 2. Structure of the thesis work.

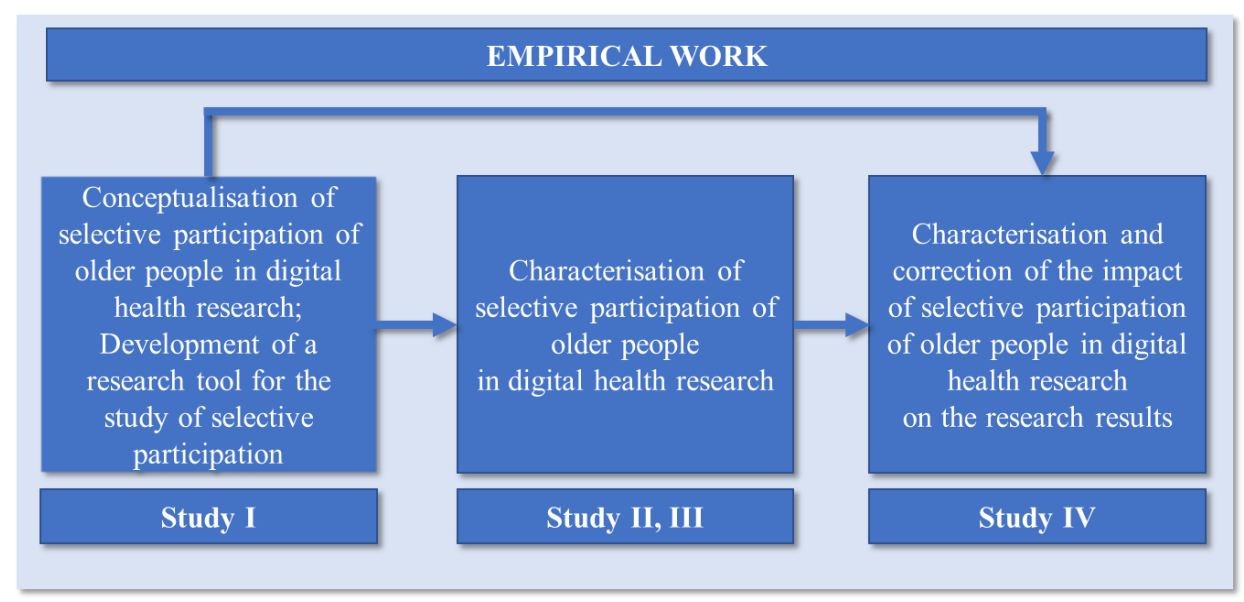

\subsection{Materials}

Within this thesis, data from two digital health intervention studies are used, namely the MIRAS project and the HF-Wii project. The two projects evaluated a mobile phone-based communication tool and an exergame technology, respectively, and targeted two different populations - namely individuals who underwent a day surgery and individuals with heart failure.

\section{THE MIRAS PROJECT}

Day surgery requires a period of postoperative surveillance after discharge from the surgery unit. Patients are usually either required to attend medical checks at the hospital or to monitor the post-operative progress by themselves at home. Mobile-based monitoring systems can facilitate the activity of self-monitoring and allow care professionals to stay in contact with the patients without arranging physical meetings (Jonathan S Abelson et al., 2017; Jonathan S. Abelson et al., 2017; Berg, Årestedt and Kjellgren, 2013).

The MIRAS project is an intervention study which evaluated a mobile phone-based system for monitoring the post-operative progress of individuals who underwent a day surgery. The MIRAS project is 
designed as a randomised controlled trial (RCT). Individuals who were eligible and willing to take part in the intervention study were consecutively included and randomized either to a post-operative monitoring through a mobile phone-based system (i.e. the intervention group) or to a traditional face-to-face post-operative monitoring at the day surgery unit (i.e. the control group). Individuals in the intervention group were invited to answer short questions on their recovery progress using their mobile phones. The mobile phone-based post-operative monitoring was mediated by a safe data system installed on the mobile phones of the participants and was conducted on days 1-14, 21, and 28 after the day surgery.

The MIRAS project was carried out in Sweden. The target population of MIRAS consisted of individuals undergoing day surgery in the fields of orthopaedics, general surgery (including breast cancer surgery), and urology, at two public day surgery units. Individuals were recruited in 2018. To be eligible to take part in the MIRAS project, individuals had to meet the following criteria: (1) having a mobile phone with internet connection, (2) being able to speak Swedish, (3) not showing/reporting other health problems which could interfere with the participation in the intervention study (e.g. aphasia, dementia), (4) being older than 18 years old.

\section{THE HF-WII PROJECT}

Exercising regularly is strongly recommended for patients with heart failure, but conventional ways of exercising (e.g. rehabilitation centre or fitness club) are often not suitable to this group of patients (Conraads et $a l ., 2012)$. Exercise programmes based on serious games can increase the level of exercise activity among patients with heart failure (Higgins et al., 2010; Verheijden Klompstra, Jaarsma and Strömberg, 2014).

The HF-Wii project is an intervention study, which evaluated the impact of exergaming on the exercise capacity and daily physical activity of patients with heart failure (Jaarsma et al., 2015). Exergame refers to a category of video-games that are used for practicing physical activity. The HF-Wii project was designed as an RCT with two groups (i.e. intervention and control). The control group was provided with a 
motivational support to exercise, while the intervention group received both the motivational support and a Nintendo Wii exercise program.

The target population of the HF-Wii project consisted of patients who were diagnosed with heart failure by a cardiologist according to European Society of Cardiology guidelines, who accessed the chosen recruitment sites between 2013 and 2017, and who were older than 18 years. Exclusion criteria for the HF-Wii intervention study were: (1) showing physical or balance problems, (2) reporting visual impairments, (3) having severe cognitive impairment(s) or psychiatric illness, (4) having a life expectancy shorter than six months, and (5) not being able to speak or understand the language of the country where the intervention study took place. Such criteria were assessed by a heart failure nurse or a physician.

The HF-Wii project collected data from several countries. This thesis used data from the HF-Wii intervention studies conducted in Germany, Italy, the Netherlands, and Sweden. More details on the HF-Wii project can be found in the relevant publications (Jaarsma et al., 2015; Jaarsma, 2020).

\subsection{A Multi-Step Approach to Participation and the NPART Research Tool (Study I)}

In this thesis, participation of older people in research is conceptualised and studied as resulting from a multi-step process during which some groups of older people are excluded from participation in the research, while others participate. The multi-step process includes three distinctive processes of selection as described in Chapter 5. These are pre-screening, recruitment, and self-selection. In the pre-screening, some individuals can be excluded prior to a formal eligibility check for reasons which are not documented, even though they belong to the target population. In the recruitment, proper screening and eligibility checks are conducted to identify eligible individuals and to exclude the ineligible ones. In the selfselection, individuals choose whether they want to participate or not in the intervention studies. All together these three processes generate a four-group structure: a non-screened group (which consists of individuals who were excluded prior to a screening phase), a non-recruited group (which consists of individuals who were screened, but not recruited), a decliner group (which consists of individuals who were screened and 
recruited but did not accept the invitation to participate), and a participant group (which consists of those individuals who were screened, recruited, and accepted to participate).

The analysis of selective participation is based on information that is collected throughout the recruitment process of study participants, starting from the identification of a target population at the recruitment sites to the enrolment of study participants, and organised according to the three processes of selection. Information comes from two main sources: recruitment data and individual survey data. Recruitment data are collected for all the individuals identified as target and include structural information based on hospital registry, such as age, gender, diagnosis, and recruitment information based on recruitment logs (e.g. recruitment status, reasons for non-recruitment, reasons for declining). Recruitment data are complemented by individual survey data collected among the eligible individuals through a dedicated research tool, that is NPART.

The NPART research tool is a survey which has been developed and piloted within this thesis work. Details can be found in Study I (Poli, Kelfve and Motel-Klingebiel, 2019). With a focus on the self-selection process, NPART targets those individuals who are indicated to be eligible to the intervention study and, thus, invited to participate. The goal of NPART is to collect information which characterises decliners and participants in order to understand which groups are more likely to accept to participate in digital health research, and which ones are less likely to do so. NPART focuses on key aspects associated with the individual decision to participate in research and includes questions on the following thematic areas: socio-demographic factors, social participation and contacts, time resources, health-related aspects, and technology familiarity. The thematic areas resulted from a review of the existing literature on factors which are associated with the individual decision to participate or not in health-related research, which was presented in Chapter 5 .

These areas are investigated by 36 questions. Most of the questions were retrieved from major ageing studies and existing surveys (e.g. Survey of Health, Ageing and Retirement in Europe (SHARE), the Minimum European Health Module (MEHM) and the World Health Organization Quality-of-Life Scale (WHOQOL-BREF)). In some cases, 
original items were adapted. Other questions were developed ad-hoc. The socio-demographic factors were investigated with seven questions on age, gender, education, job, marital status, and cohabiting. Health and subjective overall quality of life (QOL) are covered by five questions investigating self-rated health, health limitations, self-rated memory abilities, subjective overall QOL and self-reported need for support. Social participation is measured by four questions on involvement in social activities, contact with children (if relevant), contact with friends, and appropriateness of the amount of social contact. Time resources was measured by questions on job hours and caregiving. Technology familiarity was studied through questions on self-rated digital skills, level of use of digital technologies, perceived usefulness of digital health technologies. Questions were retrieved or developed in English and then translated into Swedish by a native speaker. The whole NPART instrument in Swedish was pre-piloted with two individuals of age 68 and 61 to check readability and time needed for completion. The latter was estimated to be 10-15 minutes. NPART was piloted with 70 older people. Results showed that the instrument was able to discriminate between decliners and participants and therefore can be used for investigating the individual willingness to participate in digital health research (more details on the survey, its questions, and validation can be found in the relevant publication (Poli, Kelfve and Motel-Klingebiel, 2019) available at the end of the book).

Recruitment data and individual survey data together allow, first, to detail the structure of participation and, second, to address the effect of selective participation on intervention study outcomes. The structure of participation is understood by performing comparisons between individuals who were non-screened, who were non-recruited, who declined, and who participated, by calculating (non-)participation rates, and, most importantly, by estimating whether and how the probability of being a participant varies depending on individual characteristics, such as age, gender, health. Based on the characteristics of participants, nonparticipants, and their respective probabilities to be involved, post-hoc adjustments can be performed to measure and mitigate the impact of the over-representation of some groups and of the under-representation of others on the research outcomes. A common way to do so is by applying weighting procedures (Kreuter et al., 2010; Seaman and White, 2013). 


\subsection{Examining Participation in the HF-Wii Intervention Study (Study II)}

\section{DATA}

Within HF-Wii, the analysis of selective participation was based on recruitment data which included age, gender, severity of heart failure symptoms, and information on the recruitment status. These data referred to all individuals who were screened for evaluating the HF-Wii exercise program between 2013 and 2017. Individuals were recruited in different institutional settings in Germany, Italy, the Netherlands, and Sweden. The study sample consisted overall of 1632 individuals. The mean age of the patients was 70 years ( $\mathrm{SD}=11.9$ years). More than two third of the study sample consisted of men $(64.8 \%)$, and less than one third was women $(30.3 \%)$; information on gender was missing for the remaining individuals $(4.9 \%)$.

Older people's participation in the HF-Wii intervention study was investigated as resulting from two succeeding selection processes: the recruitment according to the study requirements and the self-selection as individual decision to accept or decline the invitation to participate. The outcome variable was called 'recruitment group membership' and was constructed as a categorical variable with three categories representing the three groups in which individuals could alternatively be classified as a result of the recruitment: non-recruited, decliner, or participant. Predictor variables were age, gender, and severity of the heart failure symptoms. Age was used as a categorical variable: $\leq 64$ years, $65-69$ years, $70-79$ years, $\geq 80$ years, or missing. Gender was categorised as man, woman, or missing. The heart failure symptom severity was measured according to the NYHA Functional Classification (Levin et al., 1994) and used as a categorical variable with four categories corresponding to the four NYHA classes of symptoms severity. A missing category was also included.

Furthermore, reasons for non-recruitment and for declining were used to further explain participation and non-participation. Reasons for nonrecruitment were documented for those patients who were not eligible to participate in the intervention study based on the study criteria. Reasons for declining were available as free-text responses and coded into ten categories: not having time, working or travelling a lot, unwilling to come 
to follow-up meetings, having other illnesses, already exercising a lot, unwilling to use technical equipment or the exergame device, already have an exergame device, living between different houses (unwillingness to move the exergame equipment from place to place), shared living, and other. The category other includes those reasons which did not fit any of the previous categories.

\section{STATISTICAL ANALYSES}

Analyses comprised, first, descriptive analyses to illustrate the predictor variables on the outcome variable, and to show non-recruitment, declining, and participation rates. In order to test differences among individuals who were not recruited, who declined and who participated, one-way ANOVA and Pearson's chi-squared test were used. Second, a multinomial logistic regression was conducted to model the association between recruitment group membership and the predictors. Finally, reasons for non-recruitment and for declining were evaluated to interpret further the structure of participation in the HF-Wii project.

More details on the methods and analyses can be found in Poli et al. (2020) which is available at the end of this book.

\subsection{Examining Participation in the MIRAS Intervention Study (Study III)}

\section{DATA}

The analysis of selective participation within MIRAS is based on both recruitment data and individual survey data collected during the MIRAS recruitment process. Data refer to all individuals of age 60 years and older who were scheduled for a day surgery in the fields of orthopaedics, general surgery including breast-cancer operations, and urology at two public day surgery units in Sweden, during the timeframe of the MIRAS project in 2018. This sample included 498 individuals in total. Average age of the individuals in the sample is 70 years $(\mathrm{SD}=.32)$, median year is also 70 years. Of the 498 individuals, one third was men $(n=168)$, and two thirds were women $(n=330)$. 
For all these individuals, recruitment data were obtained. Such data included age, gender, recruitment status, and reasons for non-recruitment. Moreover, individual survey data were collected for those individuals who were screened, deemed to be eligible to participate and, thus, invited to participate in the MIRAS intervention study. This sub-group included 368 individuals of which 160 accepted to participate in MIRAS, and 208 were decliners. The NPART survey was distributed by a research nurse at the time of the invitation to the MIRAS study on the day of the surgery and collected back on the same day. Overall, 210 individuals out of 368 answered NPART (response rate $=57 \%$ ), consisting of all MIRAS participants (response rate $=100 \%$, in both control and intervention group) and 50 MIRAS decliners (response rate=24\%).

Older people's participation in the MIRAS intervention study was investigated as resulting from three processes: pre-screening, recruitment, and self-selection. Compared to Study II, information on age and gender was available also for those individuals who were excluded prior eligibility screening. This allowed to develop further the multi-step conceptual model of selective participation, as presented in Study I, and to extend it from two to three processes accounting for selective participation.

Two outcome variables were used: 'recruitment group' and 'selfselection'. Recruitment group was constructed as a categorical variable which took on four categories corresponding to the four possible recruitment groups of which individuals could alternatively be part, namely non-screened, non-recruited, declining, and participant. Selfselection was constructed as a binary variable which could take on two categories, namely refusing or participating in the MIRAS intervention study.

The following indicators were used as predictors: education measured by the International Standard Classification of Education (ISCED) and categorised as 'lower' (i.e. up to 13 years of education), 'higher' (i.e. more than 13 years of education); occupational position measured as 'white-collar jobs' and 'other positions'; partnership and cohabitation information used as a single variable with two categories 'having a partner and cohabiting' and 'other constellations'; physical and cognitive health coded as 'better' (indicating 'good' or 'very good' overall health, 'good' or 'very good' cognitive health, and 'not limited at 
all') and 'poorer' (involving all the other combinations); social participation and contacts coded as 'higher frequency' (based on 'every week' or 'daily' participation in social activities and 'daily' contacts with either children or friends, or both) and 'lower frequency' (referring to all the other combinations); self-rated digital skills in using and accessing services coded as 'high' (based on average answer was 'very good' in all the relevant items on digital skills) and 'low' (for all the other combinations); perceived usefulness of using technologies for health monitoring coded as 'high' and 'low'. Age was used as a categorical variable with the following categories: 60-64, 65-69, 70-74, and 75 years and over; gender was used as a binary variable. Finally, reasons for nonrecruitment were classified as technology-related, language-related, or health-related.

\section{STATISTICAL ANALYSES}

Analyses focused, first, on the overall recruitment. Descriptive statistics were performed to characterise the sample in terms of age and gender. Age and gender differences between non-screened, non-recruited, decliners, and participants, were tested by Pearson's chi-squared tests and one-way ANOVAs. Participation and non-participation rates were calculated. A multinomial logistic regression was calculated to describe the association between recruitment group and, age and gender. An analysis of reasons for non-recruitment was performed to further explain patterns of participation and non-participation.

Second, self-selection was further deepened. Descriptive statistics were performed to illustrate how predictors characterised decliners and participants. Differences between these two groups were tested by Pearson's chi-squared test and Student's t-test. Four logistic regression models were used to calculate the association between the individual decision to decline (or not) the invitation to participate in the MIRAS intervention study and the studied predictors.

More details on methods and analyses can be found in the relevant manuscript (Poli et al. 2021, under review) available at the end of this book. 


\subsection{Correcting the Impact of Selective Participation (Study IV)}

In Study I, II, and III, selective participation was examined conceptually and empirically. The processes leading to selective participation in digital health research were described and measured within two intervention studies evaluating digital health technologies for older people. Building on the knowledge generated by the first three studies of this thesis, Study IV investigated what are the effects of selective participation on intervention results and performed a correction for those effects. This was done in the context of the MIRAS project.

\section{DATA}

The assessment of the impact of selective participation on the MIRAS intervention results is based on recruitment data and intervention outcome data. Recruitment data were obtained for all individuals 50 years old and older who were scheduled for a day surgery in the fields of orthopaedics, general surgery including breast-cancer operations, and urology, at two units of day surgery in Sweden, during the MIRAS recruitment timeframe in 2018. These data included age, gender, and recruitment status (i.e. being non-screened, non-recruited, decliner, or participant). Participation and non-participation were interpreted according to the multi-step conceptualisation of selective participation developed and described in Study I, applied in Study II, and further detailed in Study III. Individuals were in total 717. Mean age was 65 years old $(\mathrm{SD}=9.6)$. About 51 per cent of the individuals was 65 years old or older $(n=375)$. About a third of the individuals was men $(n=256)$, and about two thirds was women $(n=461)$.

Intervention outcome data were available for all individuals who participated in the MIRAS intervention study as control or intervention group ( $\mathrm{n}=281$ in total for both groups). Intervention outcome data referred to four main outcome measures: health-related quality of life, general health status, post-surgical recovery, and individual sense of security.

Health-related QOL was measured with the EuroQoL (EQ5D) instrument (The EuroQol Group, 1990) before and after the intervention. The outcome variable for the health-related QOL was constructed as the 
difference between the EQ5D score measured at post-intervention and the EQ5D score assessed before the intervention. The general health status and post-surgical recovery were measured by the Post-discharge Surgical Recovery (PSR) instrument (Berg et al., 2010; Kleinbeck, 2000). The outcome variable for the general health status (which I will refer to as PSR8) was constructed as a measure of the difference between the postintervention score and the pre-intervention score on the health status items of the PSR. The outcome variable for the overall post-surgical recovery (which I will refer to as PSR12) was created as a variable summarising all the PSR items measured after the intervention. The individual sense of security was measured by the subscale 'mastery' of the Sense of Security in Care - Patients' Evaluation (SEC-P) instrument (Krevers and Milberg, 2014). The subscale includes the following items: 'do you feel confident that you can handle your daily life?', 'do you feel you have control over your situation?', and 'do you feel healthcare personnel have adequately informed you about what to expect in your care?'. The outcome variable for the individual sense of security was constructed as a variable which takes the mean of the three SEC-P items as values.

The following predictors were used: age, gender, and study group membership. Age was used as a categorical variable. Gender was used as a binary variable. Study group membership was a categorical variable with two groups: being in the control or in the intervention group.

In order to identify and correct for the impact of selective participation on the effects of the MIRAS intervention, four weight variables were constructed based on age and gender. Each of these weight variables were able to adjust for the over-representation and the under-representation of groups in the MIRAS intervention study, due to pre-screening, recruitment, self-selection, and allocation to control and intervention group.

\section{STATISTICAL ANALYSES}

First, descriptive statistics were performed to describe participants and non-participants (i.e. non-screened, non-recruited, and decliners) by age and gender. Pearson's chi-squared tests and one-way ANOVA were applied to test differences between the groups. Further descriptive 
statistics were performed to characterise participants in the control group and in the intervention group, in terms of age and gender. The two groups were also compared by age and gender with Pearson's chi-squared test and Student's t-test.

To test the intervention effects of MIRAS, two standard (unweighted) procedures were used. In the first standard procedure, effects were tested with four linear regression models comparing control and intervention groups on the four outcomes, namely EQ5D, PSR8, PSR12, and SEC-P. The models were controlled by age and gender. In the second standard procedure, the same four linear regression models were calculated, but the propensity score of being participant was added as a controlling variable.

To identify the effects of selective participation on the MIRAS intervention outcomes and to correct for that, a stepwise weighting procedure was applied. Four weight variables were applied in total and used one by one in the models on the four outcomes. Each weight variable is meant to adjust for a specific step of selection by reducing or increasing the relevance of the observations depending on proportions of participation. This allowed to compare individuals in the control and in the intervention group on the four outcomes (i.e. EQ5D, PSR8, PSR12, and SEC-P) while attributing different relevance to different individuals depending on whether they belong to an over-represented or an underrepresented group in the study.

Finally, because the proportions of men and women participating and not participating in the MIRAS intervention were different, separate analyses for men and women were performed. Both standard procedures for testing the intervention effects on the two gender groups and weighted procedures for identifying the effects of selective participation and for correcting were used.

More details on methods and analyses can be found in the relevant manuscript available at the end of this book. 
Arianna Poli 


\section{Chapter 7}

\section{Summary of the Results}

\subsection{Study I}

In Study I, participation in research on digital health was conceptualised, and it was defined how selective participation could be studied. Also, a survey instrument for the study of the process of self-selection was developed and piloted.

At some specific points in time along the recruitment of study participants, some individuals from the targeted population become nonparticipants, and some others become participants. Two main processes of selection were identified as responsible of this, namely recruitment and self-selection. Because processes of selections are several, selective participation in research should be thus interpreted as resulting from a multi-step process and should be studied accordingly.

The study of selective participation must be based on different sources of information. First, recruitment data, including institutional data (e.g. age, gender), are needed to describe the recruitment process and the 
structure of participation in digital health research. Second, this should be combined with individual survey data providing the individual perspective on the decision to participate (or not) in the research. A dedicated survey instrument was developed and piloted. It assesses sociodemographic, health-related, social participation, technology-related dimensions. Results of the pilot study show that the NPART survey instrument is sensitive to discriminate between participants and nonparticipants.

The proposed multi-step approach can be used for investigating selective participation in digital health research. The outcomes of the analysis of selective participation serve as a basis for the implementation of weighting strategies to correct research results for the impact of selective participation.

\subsection{Study II}

In Study II, the multi-step approach for the study of selective participation was applied within an intervention study evaluating an exergaming intervention for improving daily physical activity among individuals with heart failure, namely the HF-Wii project. Recruitment data were used to investigate whether and how participation in the intervention study was associated with gender, age, and health status (measured as heart failure symptom severity). No survey data were collected in Study II.

Results show that, compared to non-participants, participants exhibited less serious heart failure symptoms and were younger. No gender differences were found. Age and health were associated with the likelihood to participate in the intervention study (Table 1). In particular, being older was associated with increased likelihood of being nonrecruited and decliner. Showing more severe heart failure symptoms was associated with increased likelihood of being non-recruited. Individuals who were ineligible to the intervention study were most often excluded because of balance or other physical problems. Lack of time and competing tasks were most often reported as reasons for declining the invitation to participate. 
Table 1. Multinomial logistic regression model of the relationship between recruitment group membership and predictors (i.e. age, gender, and heart failure symptom severity) in the HF-Wii study.

\begin{tabular}{|c|c|c|c|c|c|c|c|c|}
\hline \multirow[b]{2}{*}{ Predictors } & \multicolumn{4}{|c|}{ Nonrecruited vs participant ${ }^{\mathrm{a}}$} & \multicolumn{4}{|c|}{ Decliner vs participant $^{\mathbf{a}}$} \\
\hline & $\beta$ & SE & $P$ value & $\operatorname{Exp}(\beta)$ & $\beta$ & SE & $P$ value & $\operatorname{Exp}(\beta)$ \\
\hline Intercept & -2.93 & .51 & .00 & $\mathrm{~N} / \mathrm{A}^{\mathrm{c}}$ & -0.64 & .26 & .01 & N/A \\
\hline \multicolumn{9}{|l|}{ Age range (years) } \\
\hline$\leq 64$ & .57 & .26 & .03 & 1.78 & .29 & .20 & .15 & 1.34 \\
\hline $65-69$ (ref.) & 0 & N/A & N/A & N/A & 0 & N/A & N/A & N/A \\
\hline $70-79$ & .46 & .25 & .07 & 1.59 & .55 & .20 & .01 & 1.74 \\
\hline$\geq 80$ & 1.35 & .27 & $<.001$ & 3.86 & .89 & .24 & $<.001$ & 2.44 \\
\hline \multicolumn{9}{|l|}{ Gender } \\
\hline Women & .19 & .16 & .24 & 1.21 & -.04 & .14 & .77 & .96 \\
\hline Men (ref) & 0 & N/A & N/A & N/A & 0 & N/A & N/A & N/A \\
\hline \multicolumn{9}{|l|}{ HF symptom severity ${ }^{d}$} \\
\hline NYHA class $I^{\mathrm{e}}$ (ref) & 0 & N/A & N/A & N/A & 0 & N/A & N/A & N/A \\
\hline NYHA class II $^{\mathrm{f}}$ & .70 & .49 & .15 & 2.02 & .03 & .23 & .91 & 1.03 \\
\hline NYHA class III ${ }^{\mathrm{g}}$ & 2.69 & .49 & $<.001$ & 14.68 & .41 & .25 & .11 & 1.51 \\
\hline NYHA class IV ${ }^{\mathrm{h}}$ & 4.03 & .72 & $<.001$ & 56.18 & .67 & .67 & .32 & 1.95 \\
\hline
\end{tabular}

Source: Retrieved from Poli et al. (2020).

\subsection{Study III}

In Study III, the full multi-step conceptual model for the analysis of participation was applied in an intervention study evaluating a mobilebased intervention for monitoring post-operative recovery of individuals who underwent a day surgery - the MIRAS project. Compared to Study I and II, the multi-step conceptual model was extended by including a further step of selection, namely the pre-screening.

Recruitment data and individual survey data were used to understand the involvement of older people in digital health research in its association with socio-demographic, health status, social participation, and technology-related indicators. 
Results show that participation is selective. Some groups are especially less likely to be involved as result of selections in prescreening, recruitment, and self-selection phases (Table 2). Compared to participants, individuals who were not screened, not recruited, and decliners, were significantly older. Individuals who were ineligible were most often excluded because of technology-related barriers (e.g. they did not have a mobile phone or had a malfunctioning mobile phone).

Table 2. Multinomial logistic regression on the association between participation and age and gender.

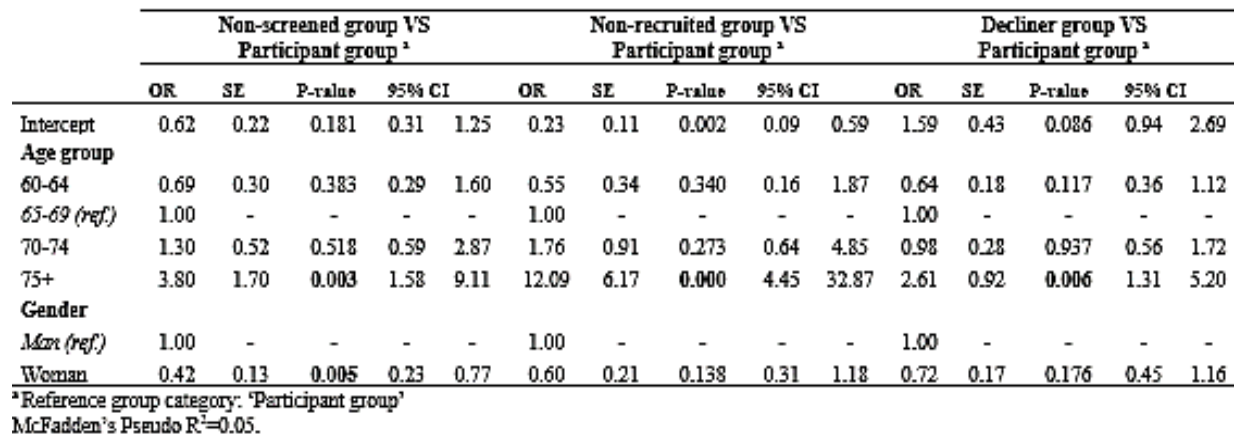

Source: Retrieved from Poli et al. (2021, under review).

Results on self-selection showed that participants and decliners were significantly different one another. Age, gender, job, health status, and digital skills were associated with the decision to take part in the MIRAS intervention study. Individuals who were younger, indicated to be women, had a white-collar job, showed a better health status, and reported higher digital skills, were more likely to accept to participate in MIRAS than their counterparts.

\subsection{Study IV}

In Study IV, the impact of selective participation on the research outcomes of MIRAS was described and corrected. Results show that selective participation modifies the research results of MIRAS. Although we found that the MIRAS intervention had a positive effect on the overall post-surgical recovery and on the individual sense of security in care, no overall intervention effects are found when correcting for the impact of selective participation. This indicates that the observed intervention 
effects represent an overestimation caused by the under-representation of some groups of older people (i.e. selective participation) that are less likely to benefit from the MIRAS intervention.

As illustrated in Study II and III, selective participation originates from three consecutive processes of selection: pre-screening, recruitment, and self-selection. In Study IV, it was found that self-selection had the largest impact on research results. Self-selection decreased the representation of those groups who obtained smaller or no effects from the intervention and increased the representation of those who gained from the intervention. By this, self-selection generated an overestimation of the positive effects of the MIRAS intervention. It was found that, compared to women, men were less likely to accept to participate in the MIRAS study and had no effect from the intervention. On the other hand, women, who were over-represented, showed significant positive effects from the intervention.

Finally, Study IV demonstrates that weighting is an effective strategy to solve or mitigate the effects of selective participation on the research outcomes and to show results which reflect better the effects of a digital health intervention within the targeted population. 
Arianna Poli 


\section{Chapter 8 \\ Discussion}

The aim of this thesis is to contribute to the understanding of mechanisms driving digital inequalities among older people, by studying the involvement of older people in research on digital technologies. The overall objective of the work was to investigate the link between the involvement of older people in evaluations of digital technologies and research outcomes, taking digital health technologies as examples.

This thesis showed that the involvement of older people in research on digital technologies can be studied as resulting from a multi-step process of selection taking place along the recruitment of study participants. Three main processes of selection exist: pre-screening (i.e. selection occurring prior to the eligibility check and for no documented reasons), recruitment (i.e. selection due to eligibility check according to exclusion/inclusion criteria of the given intervention study), and selfselection (i.e. individual decision whether to participate or not in the given intervention study). At each of these steps, some individuals are excluded, and others are not.

The findings of this thesis demonstrated that, along the multi-step process of selection, the likelihood to participate differs among groups of 
older individuals. Some groups of older people are systematically less likely to be involved than others. These groups tend to have disadvantaged social positions in terms of age, socio-economic status, health status, and digital skills. The under-representation of these groups and, thus, the over-representation of their counterparts determine the socalled selective participation in research. Selective participation leads to biased research results which overemphasise the intervention effects among the over-represented groups and mask the effects among the under-represented groups.

This thesis found that applying weighting procedures allows to characterise the impact of selective participation on the research outcomes and to correct for it. By doing this, it was found that selective participation biases research outcomes and can cause an overestimation of the positive effects of a digital health intervention due to the underrepresentation of groups of older people who do not benefit from the intervention and the over-representation of those who benefit. The overestimation of intervention effects reinforces old age digital and social inequalities, as it promotes digital health technologies which are suitable for some groups of older people but increase exclusion risks for groups of older people in lower social positions which are less likely to participate and less digitally engaged.

At the beginning of this thesis, four outcome scenarios were presented. In the light of these thesis findings, the scenario ' $(c)$ ': Participation is selective; exclusion and inequality effects can be found is confirmed. The uneven involvement of older people in digital health research is an inequality mechanism which exposes groups of older people with lower social positions to increased risks of digital exclusion compared to their counterparts. This happens through under-representing groups with lower social positions in research, biasing research outcomes, and overestimating the positive effects of digital health technologies among individuals targeted.

Research has the fundamental role of advising political decisions which affect millions of individuals. Research outcomes that fail in representing the effects of digital technologies among groups of older people who, for example, are older, have poorer health status, have lower socio-economic status, constitute an incorrect scientific basis for political decisions on digitalisation. The understanding of the impact of the 
ongoing digital shift among older people is compromised, and the ability of political decisions to sustain inclusion and to ensure good standards of living to older individuals is reduced.

From the perspective of the political economy of ageing, digitalisation policies have differential effects among older people based on social position and, by this, reinforce inequalities. Such differential effects are enabled by inequality mechanisms which introduce selectivity processes favouring some groups of older people over others, along the lines of social position. Selective participation of older people in research on digital technologies can be one of the mechanisms through which a selectivity by social position is performed, and digital and social inequalities are perpetuated. As groups of older people with lower social positions are less likely to participate in research on digital health technologies and to influence the research results, the poorer effects of digital technologies among them cannot be observed. Negative or no effects among groups with lower social positions masked by overall positive effects feed the optimism for a digital shift in healthcare and reduce the attention paid to the need for digital inclusion strategies which can increase digital participation of groups with lower social positions. In this thesis, healthcare was used as an exemplifying context in which digital technologies are having a large impact. However, it is highly likely that findings of this thesis are applicable to other domains of digital society.

This thesis has some limitations. First, the involvement of older people in digital health research was investigated within two intervention studies evaluating two specific types of digital health technologies, e.g. an exergaming technology and a mobile-based communication tool. The generalisation of the thesis findings to other types of technologies and of intervention studies should be taken cautiously. Although participation is associated with age, socio-economic status, health status, and digital skills, it could be that selective participation and its impact on the research results takes slightly different forms depending on the type of technologies evaluated and of intervention design.

Second, the study of selective participation requires information on non-participants, which can be difficult to obtain and often limited in its type. This could limit the possibilities of applying the proposed approach to participation in contexts where non-participants' information is not 
available. However, Study II demonstrates that some useful insights on selective participation can be obtained even based on recruitment data only (e.g. age, gender, diagnosis).

Third, very limited information was available on the process of prescreening. The pre-screening process became apparent during early data analyses for Study III, as the recruitment and the self-selection together were not sufficient for accounting for the discrepancy between the target population at the recruitment sites and the group of study participants. From the data, it was clear that the individuals excluded at the step of prescreening were selected out prior any formal check for the study as no documentation was available. Future studies should deepen this step of selection to understand what is behind an early and undocumented exclusion from the recruitment process.

As a fourth limitation, collecting individual survey data on nonparticipant decliners was particularly challenging, and response rates were low. In that respect, the survey itself could have suffered from a selection bias, namely those who answered the survey could differ from those who did not answer the survey. However, even in this case, the observed differences between study participants and study decliners would not be wrong but most likely an underestimation of the actual differences.

Fifth, the survey items measuring time resources and need for support did not perform well. This prevented the assessment of the association between the two indicators and the willingness to participate in the MIRAS project. Such assessment was partly possible through the analysis of the reported reasons for declining. However, such data were very limited in amount and available as pre-grouped into broad categories within Study II and not available at all within Study III.

Finally, for all the studies of this thesis, the limited number of cases reduced the statistical power of the observed associations. It is highly likely that the observed associations would have been stronger with larger samples.

Nevertheless, this thesis provides a strong conceptual, empirical, and methodological contribution to the field at the intersection of ageing, inequality, and digital technologies. It adds to the existing literature a full conceptualisation of selective participation of older people in research, 


\section{Discussion}

detailing causal processes, their functioning, and sequence. It proposes a research tool which specifies how to study, interpret, and correct for selective participation of older people in digital health research. It gives empirical demonstration of the utility and applicability of such research tool. Furthermore, findings from this thesis enrich the existing literature on mechanisms widening digital and social inequalities among older people, by providing evidence on an understudied mechanism that is selective participation of older people in research on digital technologies.

Selective participation of older people in research is a mechanism which should receive more attention when conceptualizing digital and social exclusion and inequalities. Addressing and correcting selective participation in research can avoid widening digital and social inequalities and can guide digital inclusion strategies targeting groups of older people which lag behind in a digital society.

\subsection{Conclusions}

Participation in a digital society is unequally distributed among older people and structured along the lines of characteristics such as age, education, previous job, health status. Understanding the mechanisms behind digital inequalities is imperative to avoid exacerbation of social inequalities in old age. In this thesis, the involvement of older people in digital health research was investigated as an understudied mechanism leading to digital inequalities among older people. Findings show that this is indeed a mechanism which can generate and reinforce digital inequalities by over-rating the utility of digital technologies among older people and wrongly advising digitalisation strategies.

Based on the findings of this thesis, some recommendations can be made. Researchers should implement more inclusive recruitment strategies (e.g. by focusing part of the recruitment on known underrepresented groups) and make the analysis of selective participation a structural part of intervention studies on digital technologies. This allows to produce more accurate research outcomes which reflect the diversity of the targeted populations. Older people's organisations should take part in the evaluation of digital technologies, as they can support the recruitment processes and can speak for the interests of groups of older people which are less likely to be involved in research. Policymakers 
should develop and implement digitalisation strategies based on research evidence obtained from samples which are pertinent to the population of interest in its diverse subgroups and should take into account the differential effects of digital interventions on different groups of older people. Moreover, in an ageing society, digitalisation strategies should always be accompanied by digital inclusion strategies sustaining the participation of those groups of older people which fall into the disadvantaged side of digital and social inequalities.

Finally, more research on mechanisms leading to old age digital inequalities is needed, and this should take a perspective of old age exclusion and inequalities. With digital technology access and use becoming fundamental prerequisites for participating in society, understanding the mechanisms sustaining digital inequalities among older people is crucial both to advance the scientific knowledge on the impact of digital transformation among older people and to guide precise and tailored digital inclusion interventions which reduce disparities in a digital and ageing society. 


\section{References}

Abelson, J. S., Kaufman, E., Symer, M., Peters, A., Charlson, M., \& Yeo, H. (2017). Barriers and benefits to using mobile health technology after operation: A qualitative study. Surgery, 162(3), 605-611. https://doi.org/10.1016/j.surg.2017.05.007

Abelson, J. S., Symer, M., Peters, A., Charlson, M., \& Yeo, H. (2017). Mobile health apps and recovery after surgery: What are patients willing to do? The American Journal of Surgery, 214(4), 616-622. https://doi.org/10.1016/j.amjsurg.2017.06.009 Akmatov, M. K., Jentsch, L., Riese, P., May, M., Ahmed, M. W., Werner, D., Rösel, A., Prokein, J., Bernemann, I., Klopp, N., Prochnow, B., Illig, T., Schindler, C., Guzman, C. A., \& Pessler, F. J. (2017). Motivations for (non)participation in population-based health studies among the elderly - comparison of participants and nonparticipants of a prospective study on influenza vaccination. BMC Medical Research Methodology, 17(1), 18. https://doi.org/10.1186/s12874-017-0302-z

Allemann, H., \& Poli, A. (2020). Designing and evaluating information and communication technology-based interventions? Be aware of the needs of older people. European Journal of Cardiovascular Nursing. https://doi.org/10.1177/1474515119897398

Alley, D., \& Crimmins, E. (2010). Epidemiology of ageing. Sage Handbook of Social Gerontology. London: Sage Publications, 75-95. https://doi.org/10.4135/9781446200933.n6

Alvaredo, F., Chancel, L., Piketty, T., Saez, E., \& Zucman, G. (2018). World inequality report 2018. Cambridge: Belknap Press.

Anderson, R. H. (1995). Universal Access to E-Mail: Feasibility and Societal Implications. Santa Monica: ERIC.

Atkinson, A. B. (2015). Inequality - What Can Be Done? Cambridge: Harvard University Press.

Ayalon, L., Chasteen, A., Diehl, M., Levy, B. R., Neupert, S. D., Rothermund, K., Tesch-Römer, C., \& Wahl, H.-W. (2020). Aging in Times of the COVID-19 Pandemic: Avoiding Ageism and Fostering Intergenerational Solidarity. The Journals of Gerontology: Series B. https://doi.org/10.1093/geronb/gbaa051

Baars, J., Dannefer, D., Phillipson, C., \& Walker, A. (2016). Aging, globalization and inequality: The new critical gerontology: Routledge.

Barbabella, F., Melchiorre, M. G., Quattrini, S., Papa, R., \& Lamura, G. (2017). How can eHealth improve care for people with multimorbidity in Europe (Vol. 25). Copenhagen: European Observatory on Health Systems and Policies.

Beaunoyer, E., Dupéré, S., \& Guitton, M. J. (2020). COVID-19 and digital inequalities: Reciprocal impacts and mitigation strategies. Computers in Human Behavior, 111, 106424. https://doi.org/10.1016/j.chb.2020.106424

Bengtson, V. L., Elder Jr, G. H., \& Putney, N. M. (2012). The life course perspective on ageing: Linked lives, timing, and history. Adult lives: A life course perspective, 9-17. https://doi.org/10.1017/CBO9780511610714.053

Bennett, G. G., \& Glasgow, R. E. (2009). The Delivery of Public Health Interventions via the Internet: Actualizing Their Potential. Annual Review of Public Health, 30(1), 273-292. https://doi.org/10.1146/annurev.publhealth.031308.100235 
Beresford, P. (2013). From 'other' to involved: user involvement in research: an emerging paradigm. Nordic Social Work Research, 3(2), 139-148. https://doi.org/10.1080/2156857X.2013.835138

Berg, K., Idvall, E., Nilsson, U., Årestedt, K. F., \& Unosson, M. (2010). Psychometric evaluation of the post-discharge surgical recovery scale. Journal of evaluation in clinical practice, 16(4), 794-801. https://doi.org/10.1111/j.1365-2753.2009.01197.x

Berg, K., Arestedt, K., \& Kjellgren, K. (2013). Postoperative recovery from the perspective of day surgery patients: a phenomenographic study. International journal of nursing studies, 50(12), 1630-1638. https://doi.org/10.1016/j.ijnurstu.2013.05.002

Berkowsky, R. W., \& Czaja, S. J. (2018). Challenges associated with online health information seeking among older adults. In Aging, technology and health (pp. 3148). Amsterdam: Elsevier.

Berner, J., Rennemark, M., Jogréus, C., Anderberg, P., Sköldunger, A., Wahlberg, M., Elmståhl, S., \& Berglund, J. (2014). Factors influencing Internet usage in older adults (65 years and above) living in rural and urban Sweden. Health Informatics Journal, 21(3), 237-249. https://doi.org/10.1177/1460458214521226

Bhattarai, P., \& Phillips, J. L. (2017). The role of digital health technologies in management of pain in older people: An integrative review. Arch Gerontol Geriatr, 68, 14-24. https://doi.org/10.1016/j.archger.2016.08.008

Bloom, D. E., Chatterji, S., Kowal, P., Lloyd-Sherlock, P., McKee, M., Rechel, B., Rosenberg, L., \& Smith, J. P. (2015). Macroeconomic implications of population ageing and selected policy responses. The Lancet, 385(9968), 649-657. https://doi.org/10.1016/S0140-6736(14)61464-1

Boise, L., Wild, K., Mattek, N., Ruhl, M., Dodge, H. H., \& Kaye, J. (2013). Willingness of older adults to share data and privacy concerns after exposure to unobtrusive inhome monitoring. Gerontechnology, 11(3). https://doi.org/10.4017/gt.2013.11.3.001.00

Bol, N., Helberger, N., \& Weert, J. C. M. (2018). Differences in mobile health app use: A source of new digital inequalities? The Information Society, 34(3), 183-193. https://doi.org/10.1080/01972243.2018.1438550

Bongartz, H., Rübsamen, N., Raupach-Rosin, H., Akmatov, M. K., \& Mikolajczyk, R. T. (2017). Why do people participate in health-related studies? International Journal of Public Health, 62(9), 1059-1062. https://doi.org/10.1007/s00038-017-1032-z

Boodoo, C., Zhang, Q., Ross, H. J., Alba, A. C., Laporte, A., \& Seto, E. (2020). Evaluation of a Heart Failure Telemonitoring Program Through a Microsimulation Model: Cost-Utility Analysis. J Med Internet Res, 22(10), e18917. https://doi.org/10.2196/18917

Bourgeois, F. T., Olson, K. L., Tse, T., Ioannidis, J. P., \& Mandl, K. D. (2016). Prevalence and Characteristics of Interventional Trials Conducted Exclusively in Elderly Persons: A Cross-Sectional Analysis of Registered Clinical Trials. PLOS One, 11(5), e0155948. https://doi.org/10.1371/journal.pone.0155948

Boushey, H., DeLong, J. B., \& Steinbaum, M. (2017). After Piketty: The agenda for economics and inequality. Cambridge: Harvard University Press.

Britton, A., McKee, M., Black, N., McPherson, K., Sanderson, C., \& Bain, C. (1999). Threats to applicability of randomised trials: exclusions and selective participation. 


\section{References}

Journal of Health Services Research \& Policy, 4(2), 112-121. https://doi.org/10.1177/135581969900400210

Broendum, E., Ulrik, C. S., Gregersen, T., Hansen, E. F., Green, A., \& Ringbaek, T. (2016). Barriers for recruitment of patients with chronic obstructive pulmonary disease to a controlled telemedicine trial. Health Informatics Journal, 24(2), 216224. https://doi.org/10.1177/1460458216667166

Calhoun, D., \& Lee, S. B. (2019). Computer usage and cognitive capability of older adults: Analysis of data from the Health and Retirement Study. Educational Gerontology, 45(1), 22-33. https://doi.org/10.1080/03601277.2019.1575026

Carretero, S., Stewart, J., \& Centeno, C. (2015). Information and communication technologies for informal carers and paid assistants: benefits from micro-, meso-, and macro-levels. European journal of ageing, 12(2), 163-173. https://doi.org/10.1007/s10433-015-0333-4

Castells, M. (1996). The information age: Economy, society and culture Oxford: Blackwell

Chang, B.-H., Hendricks, A. M., Slawsky, M. T., \& Locastro, J. S. (2004). Patient recruitment to a randomized clinical trial of behavioral therapy for chronic heart failure. BMC Medical Research Methodology, 4(1), 8. https://doi.org/10.1186/14712288-4-8

Chatfield, M. D., Brayne, C. E., \& Matthews, F. E. (2005). A systematic literature review of attrition between waves in longitudinal studies in the elderly shows a consistent pattern of dropout between differing studies. Journal of Clinical Epidemiology, 58(1), 13-19. https://doi.org/10.1016/j.jclinepi.2004.05.006

Chen, K., \& Chan, A. H.-S. (2013). Use or non-use of gerontechnology-A qualitative study. International journal of environmental research and public health, 10(10), 4645-4666. https://doi.org/10.3390/ijerph10104645

Chen, Y.-R. R., \& Schulz, P. J. (2016). The effect of information communication technology interventions on reducing social isolation in the elderly: A systematic review. Journal of medical Internet research, 18(1). https://doi.org/10.2196/jmir.4596

Cherubini, A., Oristrell, J., Pla, X., Ruggiero, C., Ferretti, R., Diestre, G., Clarfield, A. M., Crome, P., Hertogh, C., \& Lesauskaite, V. (2011). The persistent exclusion of older patients from ongoing clinical trials regarding heart failure. Archives of Internal Medicine, 171(6), 550-556. https://doi.org/10.1001/archinternmed.2011.31

Coley, N., Rosenberg, A., van Middelaar, T., Soulier, A., Barbera, M., Guillemont, J., Steensma, J., Igier, V., Eskelinen, M., Soininen, H., Moll van Charante, E., Richard, E., Kivipelto, M., Andrieu, S., Kivipelto, M., Sindi, S., Solomon, A., Andrieu, S., Coley, N.... (2018). Older Adults' Reasons for Participating in an eHealth Prevention Trial: A Cross-Country, Mixed-Methods Comparison. Journal of the American Medical Directors Association. https://doi.org/10.1016/j.jamda.2018.10.019

Conraads, V. M., Deaton, C., Piotrowicz, E., Santaularia, N., Tierney, S., Piepoli, M. F., Pieske, B., Schmid, J. P., Dickstein, K., \& Ponikowski, P. P. (2012). Adherence of heart failure patients to exercise: barriers and possible solutions: a position statement of the Study Group on Exercise Training in Heart Failure of the Heart Failure Association of the European Society of Cardiology. European journal of heart failure, 14(5), 451-458. https://doi.org/10.1093/eurjhf/hfs048 
Cotten, S. R., Anderson, W. A., \& McCullough, B. M. (2013). Impact of Internet Use on Loneliness and Contact with Others Among Older Adults: Cross-Sectional Analysis. Journal of Medical Internet Research, 15(2), e39. https://doi.org/10.2196/jmir.2306

Cotten, S. R., Ford, G., Ford, S., \& Hale, T. M. (2014). Internet Use and Depression Among Retired Older Adults in the United States: A Longitudinal Analysis. The Journals of Gerontology: Series B, 69(5), 763-771. https://doi.org/10.1093/geronb/gbu018

Coughlin, J. F. (2020). The Fourth Wave of Technology and Aging: Policy Innovation to Ensure Equity and Inclusion. Public Policy \& Aging Report, 30(4), 138-141. https://doi.org/10.1093/ppar/praa032

Creel, A. H., Losina, E., Mandl, L. A., Marx, R. J., Mahomed, N. N., Martin, S. D., Martin, T. L., Millett, P. J., Fossel, A. H., \& Katz, J. N. (2005). An assessment of willingness to participate in a randomized trial of arthroscopic knee surgery in patients with osteoarthritis. Contemporary Clinical Trials, 26(2), 169-178. https://doi.org/10.1016/i.cct.2004.12.010

Crimmins, E. M. (2004). Trends in the health of the elderly. Annu. Rev. Public Health, 25, 79-98. https://doi.org/10.1146/annurev.publhealth.25.102802.124401

Crimmins, E. M., \& Beltrán-Sánchez, H. (2010). Mortality and morbidity trends: is there compression of morbidity? Journals of Gerontology Series B: Psychological Sciences and Social Sciences, 66(1), 75-86. https://doi.org/10.1093/geronb/gbq088

Czaja, S. J. (2017). The Potential Role of Technology in Supporting Older Adults. Public Policy \& Aging Report, 27(2), 44-48. https://doi.org/10.1093/ppar/prx006

Czaja, S. J., Boot, W. R., Charness, N., \& Rogers, W. A. (2019). Designing for older adults: Principles and creative human factors approaches. Boca Raton, Florida: CRC press.

Damant, J., Knapp, M., Freddolino, P., \& Lombard, D. (2017). Effects of digital engagement on the quality of life of older people. Health \& Social Care in the Community, 25(6), 1679-1703. https://doi.org/10.1111/hsc.12335

Dannefer, D. (1987). Aging as intracohort differentiation: Accentuation, the Matthew effect, and the life course. Sociological Forum, 2(2), 211-236. https://doi.org/10.1007/BF01124164

Dannefer, D. (2003). Cumulative Advantage/Disadvantage and the Life Course: CrossFertilizing Age and Social Science Theory. The Journals of Gerontology: Series B, 58(6), S327-S337. https://doi.org/10.1093/geronb/58.6.S327

Dannefer, D. (2018). Systemic and Reflexive: Foundations of Cumulative Dis/Advantage and Life-Course Processes. The Journals of Gerontology: Series B, 75(6), 1249-1263. https://doi.org/10.1093/geronb/gby118

de Meijer, C., Wouterse, B., Polder, J., \& Koopmanschap, M. (2013). The effect of population aging on health expenditure growth: a critical review. European Journal of Ageing, 10(4), 353-361. https://doi.org/10.1007/s10433-013-0280-x

Deloitte Center for Health Solutions. (2015). Connected health: How digital technology is transforming health and social care. . Retrieved from London: www2.deloitte.com/content/dam/Deloitte/uk/Documents/life-sciences-healthcare/deloitte-uk-connected-health.pdf

DeSmet, A., Thompson, D., Baranowski, T., Palmeira, A., Verloigne, M., \& De Bourdeaudhuij, I. (2016). Is Participatory Design Associated with the Effectiveness 


\section{References}

of Serious Digital Games for Healthy Lifestyle Promotion? A Meta-Analysis. Journal of medical Internet research, 18(4), e94-e94. https://doi.org/10.2196/jmir.4444

DiMaggio, P., \& Garip, F. (2012). Network effects and social inequality. Annual Review of Sociology, 38, 93-118. https://doi.org/10.1146/annurev.soc.012809.102545

DiMaggio, P., Hargittai, E., Celeste, C., \& Shafer, S. (2004). From unequal access to differentiated use: A literature review and agenda for research on digital inequality. In K. Neckerman (Ed.), Social inequality (Vol. 1, pp. 355-400). New York: Russell Sage.

Ding, H., Chen, S. H., Edwards, I., Jayasena, R., Doecke, J., Layland, J., Yang, I. A., \& Maiorana, A. (2020). Effects of Different Telemonitoring Strategies on Chronic Heart Failure Care: Systematic Review and Subgroup Meta-Analysis. J Med Internet Res, 22(11), e20032. https://doi.org/10.2196/20032

Dodge, H. H., Katsumata, Y., Zhu, J., Mattek, N., Bowman, M., Gregor, M., Wild, K., \& Kaye, J. A. (2014). Characteristics associated with willingness to participate in a randomized controlled behavioral clinical trial using home-based personal computers and a webcam. Trials, 15(1), 508. https://doi.org/10.1186/1745-6215-15$\underline{508}$

Domingos, J. M., Godinho, C., Dean, J., Coelho, M., Pinto, A., Bloem, B. R., \& Ferreira, J. J. (2015). Cognitive impairment in fall-related studies in Parkinson's Disease. Journal of Parkinson's disease, 5(3), 453-469. https://doi.org/10.3233/JPD-150590

Ebrahim, S., \& Davey Smith, G. (2013). Commentary: Should we always deliberately be non-representative? International Journal of Epidemiology, 42(4), 1022-1026. https://doi.org/10.1093/ije/dyt105

Eccles, A. (2020). Remote care technologies, older people and the social care crisis in the United Kingdom: a Multiple Streams Approach to understanding the 'silver bullet' of telecare policy. Ageing and Society, 1-22. https://doi.org/10.1017/s0144686x19001776

Elder, G. H., Johnson, M. K., \& Crosnoe, R. (2003). The emergence and development of life course theory. In J. T. Mortimer \& M. J. Shanahan (Eds.), Handbook of the Life Course (pp. 3-19). Boston, MA: Springer.

Elder Jr, G. H. (1977). Family history and the life course. Journal of Family History, 2(4), 279-304. https://doi.org/10.1177/036319907700200402

Elskamp, A. B., Hartholt, K. A., Patka, P., Beeck, E. F., \& Cammen, T. J. (2012). Why older people refuse to participate in falls prevention trials: a qualitative study. $J$ Exp Gerontol, 47(4), 342-345. https://doi.org/10.1016/j.exger.2012.01.006

Elzen, H., Slaets, J. P., Snijders, T. A., \& Steverink, N. (2008). Do older patients who refuse to participate in a self-management intervention in the Netherlands differ from older patients who agree to participate? J Aging clinical experimental research, 20(3), 266-271. https://doi.org/10.1007/BF03324777

Esping-Andersen, G. (1999). Social foundations of postindustrial economies. Oxford: OUP

Estes, C. (2001). Political economy of aging: A theoretical framework. In C. L. Estes (Ed.), Social policy \& aging: A critical perspective (pp. 1-22). Thousand Oaks, California: SAGE Publications.

European Commission. (2016). Communication from the Commission to the European Parliament, the Council, the European Economic and Social Committee and the 
Committee of the Regions. EU eGovernment Action Plan 2016-2020: Accelerating the digital transformation of government. Retrieved from https://eurlex.europa.eu/legal-content/EN/TXT/?uri=CELEX\%3A52016DC0179

European Commission. (2018). Communication from the Commission to the European Parliament, the Council, the European Economic and Social Committee and the Committee of the Regions on enabling the digital transformation of health and care in the Digital Single Market; empowering citizens and building a healthier society. Retrieved from Brussels: https://eur-lex.europa.eu/legalcontent/EN/TXT/?uri=COM\%3A2018\%3A233\%3AFIN

European Commission. (2019a). The Digital Economy and Society Index (DESI). Retrieved from https://digital-strategy.ec.europa.eu/en/library/digital-economy-andsociety-index-desi-2019

European Commission. (2019b). Research and Innovation: ICT projects in Horizon $2020 . \quad$ Retrieved from Brussels: https://ec.europa.eu/newsroom/dae/document.cfm?doc_id=59974

European Commission. (2020a). Digital Economy and Society Index (DESI) 2020. Retrieved from Brussels: https://ec.europa.eu/digital-single-market/en/digitalpublic-services-scoreboard

European Commission. (2020b). eGovernment Benchmark 2020 - eGovernment that works for the people. Retrieved from Luxembourg: https://ec.europa.eu/newsroom/dae/document.cfm?doc_id=69459

European Commission. (2021a). Europe investing in digital: the Digital Europe Programme. Retrieved from https://ec.europa.eu/digital-single-market/en/europeinvesting-digital-digital-europe-programme

European Commission. (2021b). Green Paper on Ageing - Fostering Solidarity and Responsibility between Generations. Retrieved from Brussels: https://ec.europa.eu/info/sites/info/files/1_en_act_part1_v8_0.pdf

Regulation (EU) 2016/679 of the European Parliament and of the Council of 27 April 2016 on the protection of natural persons with regard to the processing of personal data and on the free movement of such data, and repealing Directive 95/46/EC (General Data Protection Regulation) (2016).

Eurostat. (2017). People in the EU - statistics on an ageing society. Retrieved from https://ec.europa.eu/eurostat/statisticsexplained/index.php?title=People in the EU_ _ statistics on an ageing society

Eurostat. (2021). Digital economy and society. Retrieved from: https://ec.europa.eu/eurostat/web/digital-economy-and-society/data/database

Evangelista, R., Guerrieri, P., \& Meliciani, V. (2014). The economic impact of digital technologies in Europe. Economics of Innovation and New Technology, 23(8), 802824. https://doi.org/10.1080/10438599.2014.918438

Fang, M. L., Canham, S. L., Battersby, L., Sixsmith, J., Wada, M., \& Sixsmith, A. (2018). Exploring Privilege in the Digital Divide: Implications for Theory, Policy, and Practice. The Gerontologist, 59(1), e1-e15. https://doi.org/10.1093/geront/gny037

Ferraro, K. F., Shippee, T. P., \& Schafer, M. H. (2009). Cumulative inequality theory for research on aging and the life course. New York: Springer Publishing Co.

Fischl, C., Lindelöf, N., Lindgren, H., \& Nilsson, I. (2020). Older adults' perceptions of contexts surrounding their social participation in a digitalized society-an 


\section{References}

exploration in rural communities in Northern Sweden. European Journal of Ageing. https://doi.org/10.1007/s10433-020-00558-7

Flink, M., Brandberg, C., \& Ekstedt, M. (2019). Why patients decline participation in an intervention to reduce re-hospitalization through patient activation: whom are we missing? Trials, 20(1), 82. https://doi.org/10.1186/s13063-019-3187-9

Forsman, A. K., Nordmyr, J., Matosevic, T., Park, A.-L., Wahlbeck, K., \& McDaid, D. (2017). Promoting mental wellbeing among older people: technology-based interventions. Health promotion international, 33(6), 1042-1054. https://doi.org/10.1093/heapro/dax047

Foster, A., Horspool, K. A., Edwards, L., Thomas, C. L., Salisbury, C., Montgomery, A. A., \& O'Cathain, A. (2015). Who does not participate in telehealth trials and why? A cross-sectional survey. Trials, 16(1), 258. https://doi.org/10.1186/s13063015-0773-3

Foster, L. (2012). Using a political economy and life course approach to understand gendered pension provision in the UK. Sociology Compass, 6(11), 883-896. https://doi.org/10.1111/j.1751-9020.2012.00504.x

Fowler Jr, F. J. (2013). Survey research methods. New York: Sage publications.

Francis, J., Ball, C., Kadylak, T., \& Cotten, S. R. (2019). Aging in the Digital Age: Conceptualizing Technology Adoption and Digital Inequalities. In B. B. Neves \& F. Vetere (Eds.), Ageing and Digital Technology (pp. 35-49). Springer Singapore: Springer Nature Singapore Pte Ltd.

Franklin, N. C., Lavie, C. J., \& Arena, R. A. (2015). Personal health technology: A new era in cardiovascular disease prevention. Postgraduate medicine, 127(2), 150-158. https://doi.org/10.1080/00325481.2015.1015396

Freeman, S., Marston, H. R., Olynick, J., Musselwhite, C., Kulczycki, C., Genoe, R., \& Xiong, B. (2020). Intergenerational Effects on the Impacts of Technology Use in Later Life: Insights from an International, Multi-Site Study. International Journal of Environmental Research and Public Health, 17(16), 5711. https://doi.org/10.3390/ijerph17165711

Friedel, R. D. (2007). A culture of improvement: technology and the Western millennium. Cambridge, Mass.: MIT Press.

Friemel, T. N. (2016). The digital divide has grown old: Determinants of a digital divide among seniors. New media \& society, 18(2), 313-331. https://doi.org/10.1177/1461444814538648

Gaertner, B., Seitz, I., Fuchs, J., Busch, M. A., Holzhausen, M., Martus, P., \& ScheidtNave, C. J. B. G. (2016). Baseline participation in a health examination survey of the population 65 years and older: who is missed and why? , 16(1), 21. https://doi.org/10.1186/s12877-016-0185-6

Gallistl, V., \& Nimrod, G. (2019). Online Leisure and Wellbeing in Later Life. In Perspectives on Human-Computer Interaction Research with Older People (pp. 139154). Cham: Springer.

Gallistl, V., Rohner, R., Seifert, A., \& Wanka, A. (2020). Configuring the older nonuser: Between research, policy and practice of digital exclusion. Social Inclusion, 8(2), 233-243. https://doi.org/10.17645/si.v8i2.2607

Gell, N. M., Rosenberg, D. E., Demiris, G., LaCroix, A. Z., \& Patel, K. V. (2015). Patterns of technology use among older adults with and without disabilities. Gerontologist, 55. https://doi.org/10.1093/geront/gnt166 
Gellis, Z. D., Kenaley, B., McGinty, J., Bardelli, E., Davitt, J., \& Ten Have, T. (2012). Outcomes of a telehealth intervention for homebound older adults with heart or chronic respiratory failure: a randomized controlled trial. The Gerontologist, 52(4), 541-552. https://doi.org/10.1093/geront/gnr134

Ghulam Sarwar Shah, S., \& Robinson, I. (2006). User involvement in health care technology development and assessment : Structured literature review. International Journal of Health Care Quality Assurance(6), 500. https://doi.org/10.1108/09526860610687619

Giddens, A. (2013). New rules of sociological method: A positive critique of interpretative sociologies. Hoboken, New Jersey: John Wiley \& Sons.

Gilleard, C., \& Higgs, P. (2020). Precarity and the assumption of rising insecurity in later life: a critique. Ageing and Society, 40(9), 1849-1866. https://doi.org/10.1017/S0144686X19000424

Glasgow, R. E. (2007). eHealth evaluation and dissemination research. American Journal of Preventive Medicine, 32(5), S119-S126. https://doi.org/10.1016/j.amepre.2007.01.023

Glasgow, R. E., \& Chambers, D. (2012). Developing Robust, Sustainable, Implementation Systems Using Rigorous, Rapid and Relevant Science. Clinical and Translational Science, 5(1), 48-55. https://doi.org/10.1111/j.17528062.2011.00383.x

Gollhofer, S. M., Wiskemann, J., Schmidt, M. E., Klassen, O., Ulrich, C. M., Oelmann, J., Hof, H., Potthoff, K., \& Steindorf, K. (2015). Factors influencing participation in a randomized controlled resistance exercise intervention study in breast cancer patients during radiotherapy. BMC Cancer, 15(1), 186. https://doi.org/10.1186/s12885-015-1213-1

Grand View Research. (2016). eHealth Market Analysis By Product (EHR, ePrescribing, Clinical Decision Support, Telemedicine, Consumer Health Information, mHealth, Health Management, Information System), By Services (Monitoring, Diagnostic, health care Strengthening), By End-Use (Providers, Insurers, Government, health care Consumers) And Segment Forecasts To 2022. Retrieved from https://www.grandviewresearch.com/industry-analysis/e-healthmarket

Grand View Research. (2018). mHealth Market Analysis Report By Participants (Mobile Operators, Device Vendors, health care Providers), By Service (Diagnosis, Monitoring, health care Systems), And Segment Forecasts, 2018 - 2025. Retrieved from https://www.grandviewresearch.com/industry-analysis/mhealth-market

Grates, M. G., Heming, A.-C., Vukoman, M., Schabsky, P., \& Sorgalla, J. (2018). New Perspectives on User Participation in Technology Design Processes: An Interdisciplinary Approach. The Gerontologist, 59(1), 45-57. https://doi.org/10.1093/geront/gny112

Green, B. B., Anderson, M. L., Ralston, J. D., Catz, S., Fishman, P. A., \& Cook, A. J. (2011). Patient ability and willingness to participate in a web-based intervention to improve hypertension control. Journal of Medical Internet Research, 13(1), e1. https://doi.org/10.2196/jmir.1625

Grenier, A., \& Phillipson, C. (2018). Precarious Aging: Insecurity and Risk in Late Life. Hastings Center Report, 48(S3), S15-S18. https://doi.org/10.1002/hast.907 


\section{References}

Grenier, A., \& Phillipson, C. (2020). Precarity and Ageing: Understanding Insecurity and Risk in Later Life. Bristol: Policy Press.

Grenier, A., Phillipson, C., Rudman, D. L., Hatzifilalithis, S., Kobayashi, K., \& Marier, P. (2017). Precarity in late life: Understanding new forms of risk and insecurity. Journal of Aging Studies, 43, 9-14. https://doi.org/10.1016/j.jaging.2017.08.002

Guillén, M. F., \& Suárez, S. L. (2005). Explaining the Global Digital Divide: Economic, Political and Sociological Drivers of Cross-National Internet Use. Social Forces, 84(2), 681-708. https://doi.org/10.1353/sof.2006.0015

Gulliford, M., \& Alageel, S. (2019). Digital health intervention at older ages. The Lancet Digital Health, 1(8), e382-e383. https://doi.org/10.1016/s2589-7500(19)30194-3

Halford, S., \& Savage, M. (2010). RECONCEPTUALIZING DIGITAL SOCIAL INEQUALITY. Information, Communication \& Society, 13(7), 937-955. https://doi.org/10.1080/1369118X.2010.499956

Hargittai, E. (2002). Second-level digital divide: Differences in people's online skills. First monday, 7(4). https://doi.org/10.5210/fm.v7i4.942

Hargittai, E. (2018). Potential Biases in Big Data: Omitted Voices on Social Media. Social Science Computer Review, 38(1), 10-24. https://doi.org/10.1177/0894439318788322

Hargittai, E., \& Dobransky, K. (2017). Old dogs, new clicks: Digital inequality in skills and uses among older adults. Canadian Journal of Communication, 42(2). https://doi.org/10.22230/cjc.2017v42n2a3176

Hargittai, E., Piper, A. M., \& Morris, M. R. (2018). From internet access to internet skills: digital inequality among older adults. Universal Access in the Information Society. https://doi.org/10.1007/s10209-018-0617-5

Hargittai, E., Piper, A. M., \& Morris, M. R. (2019). From internet access to internet skills: digital inequality among older adults. Universal Access in the Information Society, 18(4), 881-890. https://doi.org/10.1007/s10209-018-0617-5

Harrison, J. M., Jung, M., Lennie, T. A., Moser, D. K., Smith, D. G., Dunbar, S. B., Ronis, D. L., Koelling, T. M., Giordani, B., Riley, P. L., \& Pressler, S. J. (2016). Refusal to participate in heart failure studies: do age and gender matter? , 25(7-8), 983-991. https://doi.org/doi:10.1111/jocn.13135

Harrison, J. M., Jung, M., Lennie, T. A., Moser, D. K., Smith, D. G., Dunbar, S. B., Ronis, D. L., Koelling, T. M., Giordani, B., Riley, P. L., \& Pressler, S. J. (2016). Refusal to participate in heart failure studies: do age and gender matter? Journal of Clinical Nursing, 25(7-8), 983-991. https://doi.org/10.1111/jocn.13135

Harvey, J. T., Charity, M. J., Sawyer, N. A., \& Eime, R. M. (2018). Non-response bias in estimates of prevalence of club-based sport participation from an Australian national physical activity, recreation and sport survey. BMC Public Health, 18(1). https://doi.org/10.1186/s12889-018-5793-y

Headrick, D. R. (2009). Technology: A world history: Oxford University Press.

Heart, T., \& Kalderon, E. (2013). Older adults: Are they ready to adopt health-related ICT? International Journal of Medical Informatics, 82(11), e209-e231. https://doi.org/10.1016/j.ijmedinf.2011.03.002

Hedman, A., Nygård, L., Almkvist, O., \& Kottorp, A. (2015). Amount and type of everyday technology use over time in older adults with cognitive impairment. Scandinavian Journal of Occupational Therapy, 22(3), 196-206. https://doi.org/10.3109/11038128.2014.982172 
Helbig, N., Ramón Gil-García, J., \& Ferro, E. (2009). Understanding the complexity of electronic government: Implications from the digital divide literature. Government Information Quarterly, 26(1), 89-97. https://doi.org/10.1016/j.giq.2008.05.004

Hendra, R., \& Hill, A. (2019). Rethinking Response Rates: New Evidence of Little Relationship Between Survey Response Rates and Nonresponse Bias. Evaluation Review, 43(5), 307-330. https://doi.org/10.1177/0193841x18807719

Higgins, H. C., Horton, J. K., Hodgkinson, B. C., \& Muggleton, S. B. (2010). Lessons learned: Staff perceptions of the Nintendo Wii as a health promotion tool within an aged-care and disability service. Health promotion journal of Australia, 21(3), 189195. https://doi.org/10.1071/he10189

Holgersson, J., \& Söderström, E. (2019). Bridging the gap: Exploring elderly citizens' perceptions of digital exclusion. Paper presented at the 27th European Conference on Information Systems (ECIS), Stockholm \& Uppsala, Sweden, June 8-14, 2019.

Holman, D., \& Walker, A. (2020). Understanding unequal ageing: towards a synthesis of intersectionality and life course analyses. European Journal of Ageing. https://doi.org/10.1007/s10433-020-00582-7

Hong, Y. A., \& Cho, J. (2016). Has the Digital Health Divide Widened? Trends of Health-Related Internet Use Among Older Adults From 2003 to 2011. The Journals of Gerontology: Series B, 72(5), 856-863. https://doi.org/10.1093/geronb/gbw100

Hunsaker, A., \& Hargittai, E. (2018). A review of Internet use among older adults. New Media \& Society, 20(10), 3937-3954. https://doi.org/10.1177/1461444818787348

Hyde, M., \& Higgs, P. (2016). Ageing and globalisation. Bristol: Policy Press.

Jaarsma, T., Klompstra, L., Ben Gal, T., Boyne, J., Vellone, E., Bäck, M., Dickstein, K., Fridlund, B., Hoes, A., \& Piepoli, M. F. (2015). Increasing exercise capacity and quality of life of patients with heart failure through Wii gaming: the rationale, design and methodology of the HF-Wii study; a multicentre randomized controlled trial. European journal of heart failure, 17(7), 743-748. https://doi.org/10.1002/ejhf.305

Jaarsma, T., Klompstra, L., Ben Gal T., Ben Avraham, B., Boyne, J., Bäck, M., Chiala, O., Dickstein, K., Evangelista, L., Hagenow, A., Hoes, AW, Hägglund, E., Piepoli, M., Vellone, E., Zuithoff, N.P.A., Mårtensson, J., Stromberg, A. (2020). Effects of exergaming on exercise capacity in patients with heart failure: Results of an international multicenter randomised controlled trial (in press). Eur J Heart Fail. https://doi.org/10.1002/EJHF.1754

Jiang, X., Ming, W.-K., \& You, J. H. S. (2019). The Cost-Effectiveness of Digital Health Interventions on the Management of Cardiovascular Diseases: Systematic Review. J Med Internet Res, 21(6), e13166. https://doi.org/10.2196/13166

Karlawish, J., Cary, M. S., Rubright, J., \& TenHave, T. (2008). How redesigning AD clinical trials might increase study partners' willingness to participate. Neurology, 71(23), 1883-1888. https://doi.org/10.1212/01.wnl.0000336652.05779

Kelfve, S. (2019). Underestimated Health Inequalities Among Older People-A Consequence of Excluding the Most Disabled and Disadvantaged. The Journals of Gerontology: Series B, 74(8), e125-e134. https://doi.org/10.1093/geronb/gbx032

Kelfve, S., Thorslund, M., \& Lennartsson, C. (2013). Sampling and non-response bias on health-outcomes in surveys of the oldest old. European journal of ageing, 10(3), 237-245. https://doi.org/10.1007/s10433-013-0275-7

Keränen, N. S., Kangas, M., Immonen, M., Similä, H., Enwald, H., Korpelainen, R., \& Jämsä, T. (2017). Use of Information and Communication Technologies Among 


\section{References}

Older People With and Without Frailty: A Population-Based Survey. Journal of Medical Internet Research, 19(2), e29. https://doi.org/10.2196/jmir.5507

Khilnani, A., Schulz, J., \& Robinson, L. (2020). The COVID-19 pandemic: new concerns and connections between eHealth and digital inequalities. Journal of Information, Communication and Ethics in Society, 18(3), 393-403. https://doi.org/10.1108/jices-04-2020-0052

Khosravi, P., \& Ghapanchi, A. H. (2016). Investigating the effectiveness of technologies applied to assist seniors: A systematic literature review. International Journal of Medical Informatics, 85(1), 17-26. https://doi.org/10.1016/j.ijmedinf.2015.05.014

Kitsiou, S., Paré, G., Jaana, M., \& Gerber, B. (2017). Effectiveness of mHealth interventions for patients with diabetes: An overview of systematic reviews. PLOS ONE, 12(3), e0173160. https://doi.org/10.1371/journal.pone.0173160

Kleinbeck, S. V. (2000). Self-reported at-home postoperative recovery. Research in nursing \& health, 23(6), 461-472. https://doi.org/10.1002/1098240X(200012)23:6<461::AID-NUR5>3.0.CO;2-S

Knudsen, A. K., Hotopf, M., Skogen, J. C., Overland, S., \& Mykletun, A. (2010). The Health Status of Nonparticipants in a Population-based Health Study: The Hordaland Health Study. American Journal of Epidemiology, 172(11), 1306-1314. https://doi.org/10.1093/aje/kwq257

Kohut, A., Keeter, S., Doherty, C., Dimock, M., \& Christian, L. (2012). Assessing the representativeness of public opinion surveys. Retrieved from Washington, DC: https://www.pewresearch.org/politics/2012/05/15/assessing-the-representativenessof-public-opinion-surveys/

Konig, R., Seifert, A., \& Doh, M. (2018). Internet use among older Europeans: an analysis based on SHARE data. Universal Access in the Information Society, 17(3), 621-633. https://doi.org/10.1007/s10209-018-0609-5

Kreuter, F., Olson, K., Wagner, J., Yan, T., Ezzati-Rice, T. M., Casas-Cordero, C., Lemay, M., Peytchev, A., Groves, R. M., \& Raghunathan, T. E. (2010). Using proxy measures and other correlates of survey outcomes to adjust for non-response: examples from multiple surveys. Journal of the Royal Statistical Society: Series A (Statistics in Society), 173(2), 389-407. https://doi.org/10.1111/j.1467985X.2009.00621.X

Kummervold, P. E., Chronaki, C. E., Lausen, B., Prokosch, H.-U., Rasmussen, J., Santana, S., Staniszewski, A., \& Wangberg, S. C. (2008). eHealth trends in Europe 2005-2007: a population-based survey. Journal of medical Internet research, 10(4), e42-e42. https://doi.org/10.2196/jmir.1023

König, R., Seifert, A., \& Doh, M. J. U. A. i. t. I. S. (2018). Internet use among older Europeans: an analysis based on SHARE data. 17(3), 621-633. https://doi.org/10.1007/s10209-018-0609-5

Levin, R., Dolgin, M., Fox, C., \& Gorlin, R. (1994). Nomenclature and criteria for diagnosis of diseases of the heart and great vessels / The Criteria Committee of the New York Heart Association (M. Dolgin Ed. 9th ed. ed. Vol. 9). Boston.

Levine, D. M., Lipsitz, S. R., \& Linder, J. A. (2016). Trends in seniors' use of digital health technology in the United States, 2011-2014. Jama, 316(5), 538-540. https://doi.org/10.1001/jama.2016.9124

Lloyd-Williams, F., Mair, F., Shiels, C., Hanratty, B., Goldstein, P., Beaton, S., Capewell, S., Lye, M., Mcdonald, R., \& Roberts, C. (2003). Why are patients in 
clinical trials of heart failure not like those we see in everyday practice? Journal of clinical epidemiology, 56(12), 1157-1162. https://doi.org/10.1016/s08954356(03)00205-1

Lloyd, L. (2012). Health and care in ageing societies: a new international approach. Bristol: Policy Press.

Lupton, D. (2014). Health promotion in the digital era: a critical commentary. Health Promotion International, 30(1), 174-183. https://doi.org/10.1093/heapro/dau091

Lupton, D. (2016). Digital risk society. The Routledge handbook of risk studies, 301309.

Lutz, C. (2019). Digital inequalities in the age of artificial intelligence and big data. Human Behavior and Emerging Technologies, 1(2), 141-148. https://doi.org/10.1002/hbe2.140

Macdonald, B., \& Hülür, G. (2020). Internet Adoption in Older Adults: Findings from the Health and Retirement Study. Cyberpsychology, Behavior, and Social Networking. https://doi.org/10.1089/cyber.2019.0736

Mair, F. S., Goldstein, P., Shiels, C., Roberts, C., Angus, R., O’Connor, J., Haycox, A., \& Capewell, S. (2006). Recruitment difficulties in a home telecare trial. Journal of Telemedicine and Telecare, 12(1_suppl), 26-28. https://doi.org/10.1258/135763306777978371

Mannheim, I., Schwartz, E., Xi, W., Buttigieg, S. C., McDonnell-Naughton, M., Wouters, E. J. M., \& Van Zaalen, Y. (2019). Inclusion of Older Adults in the Research and Design of Digital Technology. International Journal of Environmental Research and Public Health, 16(19), 3718. https://doi.org/10.3390/ijerph16193718

Mariën, I., \& Prodnik, J. A. (2014). Digital inclusion and user (Dis)empowerment: A critical perspective. Info, 16(6), 35-47. https://doi.org/10.1108/info-07-2014-0030

Marshall, V. W., \& Clarke, P. J. (2010). Agency and social structure in aging and life course research. In D. Dannefer \& C. Phillipson (Eds.), The Sage handbook of social gerontology (pp. 294-305). Thousand Oaks, California: SAGE Publications Ltd.

Marx, I., Nolan, B., \& Olivera, J. (2015). The welfare state and antipoverty policy in rich countries. In A. A. a. F. Bourguignon (Ed.), Handbook of income distribution (Vol. 2, pp. 2063-2139). North Holland: Elsevier.

Matthews, K., Nazroo, J., \& Marshall, A. (2019). Digital inclusion in later life: cohort changes in internet use over a ten-year period in England. Ageing and Society, 39(9), 1914-1932. https://doi.org/10.1017/S0144686X18000326

Mazzucato, M. (2014). The entrepreneurial state: Debunking public vs. private sector myths (Vol. 1). London: Anthem Press.

McMullin, J. A., \& Marshall, V. W. (1999). Structure and agency in the retirement process: A case study of Montreal garment workers. In R. C.D. \& M. V.W. (Eds.), The self and society in aging processes (pp. 305-338). New York: Springer.

Melchiorre, M. G., Papa, R., Rijken, M., van Ginneken, E., Hujala, A., \& Barbabella, F. (2017). eHealth in integrated care programs for people with multimorbidity in Europe: insights from the ICARE4EU project. Health Policy, 122(1), 53-63. https://doi.org/10.1016/j.healthpol.2017.08.006

Merkel, S., \& Kucharski, A. (2018). Participatory Design in Gerontechnology: a systematic literature review. The Gerontologist, 59(1), e16-e25. https://doi.org/10.1093/geront/gny034 


\section{References}

Merrell, R. C., \& Doarn, C. R. (2018). Artificial Intelligence Reconsidered. Telemedicine and e-Health, 93-93. https://doi.org/10.1089/tmj.2018.29001.crd

Merton, R. K. (1968). The Matthew effect in science: The reward and communication systems of science are considered. Science, 159(3810), 56-63. https://doi.org/10.1126/science.159.3810.56

Michelet, M., Lund, A., \& Sveen, U. (2014). Strategies to recruit and retain older adults in intervention studies: A quantitative comparative study. Archives of Gerontology and Geriatrics, 59(1), 25-31. https://doi.org/10.1016/j.archger.2014.03.002

Minkler, M., \& Estes, C. L. (2019). Readings in the political economy of aging. London: Routledge.

Mitzner, T. L., Rogers, W. A., Fisk, A. D., Boot, W. R., Charness, N., Czaja, S. J., \& Sharit, J. (2016). Predicting older adults' perceptions about a computer system designed for seniors. Universal Access in the Information Society, 15(2), 271-280. https://doi.org/10.1007/s10209-014-0383-y

Mitzner, T. L., Savla, J., Boot, W. R., Sharit, J., Charness, N., Czaja, S. J., \& Rogers, W. A. (2018). Technology Adoption by Older Adults: Findings From the PRISM Trial. The Gerontologist, 59(1), 34-44. https://doi.org/10.1093/geront/gny113

Mort, M., Roberts, C., \& Callén, B. (2013). Ageing with telecare: care or coercion in austerity? Sociology of health \& illness, 35(6), 799-812. https://doi.org/10.1111/j.1467-9566.2012.01530.x

Murray, E., Hekler, E. B., Andersson, G., Collins, L. M., Doherty, A., Hollis, C., Rivera, D. E., West, R., \& Wyatt, J. C. (2016). Evaluating Digital Health Interventions: Key Questions and Approaches. American Journal of Preventive Medicine, 51(5), 843851. https://doi.org/10.1016/j.amepre.2016.06.008

Neves, B. B., Amaro, F., \& Fonseca, J. R. S. (2013). Coming of (Old) Age in the Digital Age: ICT Usage and Non-Usage among Older Adults. Sociological Research Online, 18(2), 1-14. https://doi.org/10.5153/sro.2998

Nimrod, G. (2019). Aging Well in the Digital Age: Technology in Processes of Selective Optimization with Compensation. The Journals of Gerontology: Series B, 75(9), 2008-2017. https://doi.org/10.1093/geronb/gbz111

Normansell, R., Holmes, R., Victor, C., Cook, D. G., Kerry, S., Iliffe, S., Ussher, M., Fox-Rushby, J., Whincup, P., \& Harris, T. (2016). Exploring non-participation in primary care physical activity interventions: PACE-UP trial interview findings. Trials, 17, 178-178. https://doi.org/10.1186/s13063-016-1299-z

OECD. (2015). In it together: Why less inequality benefits all. Paris: OECD Publishing.

OECD. (2016). OECD Science, Technology and Innovation Outlook 2016. Paris: OECD Publishing.

OECD. (2017a). OECD Digital Economy Outlook 2017. Paris: OECD Publishing.

OECD. (2017b). Preventing Ageing Unequally. Paris: OECD Publishing.

Olsson, T., Samuelsson, U., \& Viscovi, D. (2017). At risk of exclusion? Degrees of ICT access and literacy among senior citizens. Information, Communication \& Society, 22(1), 1-18. https://doi.org/10.1080/1369118X.2017.1355007

Olsson, T., \& Viscovi, D. (2020). Who Actually Becomes a Silver Surfer? Prerequisites for Digital Inclusion. Javnost - The Public, 27(3), 230-246. https://doi.org/10.1080/13183222.2020.1794403 
Ossebaard, H., van Gemert-Pijnen, L., de Bruijn, A., \& Geertsma, R. (2012). Magnitude of ehealth technology risks largely unknown. Retrieved from Bilthoven: https://research.utwente.nl/en/publications/magnitude-risks-of-ehealthtechnologies-largely-unknown

Palmas, W., Teresi, J., Morin, P., Wolff, L. T., Field, L., Eimicke, J. P., Capps, L., Prigollini, A., Orbe, I., \& Weinstock, R. S. (2006). Recruitment and enrollment of rural and urban medically underserved elderly into a randomized trial of telemedicine case management for diabetes care. J Telemedicine Journal e-Health, 12(5), 601-607. https://doi.org/10.1089/tmj.2006.12.601

Panek, I., Crumley, E. T., Ishigami-Doyle, Y., Sixsmith, J., Kontos, P., O’Doherty, K., \& Kirkland, S. (2017). Levels of Older Adults' Engagement in Technology Research, Design and Development: a Scoping Review. Innovation in Aging, 1(suppl_1), 393-393. https://doi.org/10.1093/geroni/igx004.1423

Perez, C. (2009). Technological revolutions and techno-economic paradigms. Cambridge Journal of Economics, 34(1), 185-202. https://doi.org/10.1093/cje/bep051

Phillipson, C. (2013). Ageing. Hoboken, New Jersey: John Wiley \& Sons.

Phillipson, C., \& Baars, J. (2007). Social theory and social ageing. In John Bond, Sheila Peace, F. Dittmann-Kohli, \& G. J. Westerhof (Eds.), Ageing in societies: European Perspectives on Gerontology (pp. 68-84). New York: SAGE Publications Ltd.

Piketty, T. (2014). Capital in the Twenty-First Century. Cambridge, Massachussets: Harvard University Press.

Piketty, T. (2020). Capital and ideology. Cambridge: Harvard University Press.

Pirhonen, J., Lolich, L., Tuominen, K., Jolanki, O., \& Timonen, V. (2020). "These devices have not been made for older people's needs" - Older adults' perceptions of digital technologies in Finland and Ireland. Technology in Society, 62, 101287. https://doi.org/10.1016/j.techsoc.2020.101287

Poli, A., Kelfve, S., Klompstra, L., Strömberg, A., Jaarsma, T., \& Motel-Klingebiel, A. (2020). Prediction of (Non)Participation of Older People in Digital Health Research: Exergame Intervention Study. J Med Internet Res, 22(6), e17884. https://doi.org/10.2196/17884

Poli, A., Kelfve, S., \& Motel-Klingebiel, A. (2019). A research tool for measuring nonparticipation of older people in research on digital health. BMC public health, 19(1), 1487. https://doi.org/10.1186/s12889-019-7830-X

Provencher, V., Mortenson, W. B., Tanguay-Garneau, L., Bélanger, K., \& Dagenais, M. (2014). Challenges and strategies pertaining to recruitment and retention of frail elderly in research studies: A systematic review. Archives of Gerontology and Geriatrics, 59(1), 18-24. https://doi.org/10.1016/j.archger.2014.03.006

Quadagno, J., Kail, B. L., \& Shekha, K. R. (2011). Welfare states: Protecting or risking old age. In Linda George \& K. Ferraro (Eds.), Handbook of sociology of aging (pp. 321-332). New York: Springer.

Quadagno, J., \& Reid, J. (1999). The political economy perspective in aging. In L. Vern, V. L. Bengtson, \& W. Warner Schaie (Eds.), Handbook of theories of aging (pp. 344-358). New York: Springer.

Reiners, F., Sturm, J., Bouw, L. J. W., \& Wouters, E. J. M. (2019). Sociodemographic factors influencing the use of ehealth in people with chronic diseases. International 


\section{References}

Journal of Environmental Research and Public Health, 16(4). https://doi.org/10.3390/ijerph16040645

Reisdorf, B., \& Rhinesmith, C. (2020). Digital Inclusion as a Core Component of Social Inclusion. Social Inclusion, 8(2), 132-137. https://doi.org/10.17645/si.v8i2.3184

Richiardi, L., Pizzi, C., \& Pearce, N. (2013). Commentary: Representativeness is usually not necessary and often should be avoided. International Journal of Epidemiology, 42(4), 1018-1022. https://doi.org/10.1093/ije/dyt103

Robinson, L., Cotten, S. R., Ono, H., Quan-Haase, A., Mesch, G., Chen, W., Schulz, J., Hale, T. M., \& Stern, M. J. (2015). Digital inequalities and why they matter. Information, Communication \& Society, 18(5), 569-582. https://doi.org/10.1080/1369118X.2015.1012532

Ross, J., Stevenson, F., Lau, R., \& Murray, E. (2016). Factors that influence the implementation of e-health: a systematic review of systematic reviews (an update). Implementation Science, 11(1), 146. https://doi.org/10.1186/s13012-016-0510-7

Rothman, K., Hatch, E., \& Gallacher, J. (2014). Representativeness is not helpful in studying heterogeneity of effects across subgroups. International Journal of Epidemiology, 43(2), 633-634. https://doi.org/10.1093/ije/dyt265

Rothman, K. J., Gallacher, J. E., \& Hatch, E. E. (2013). Why representativeness should be avoided. International Journal of Epidemiology, 42(4), 1012-1014. https://doi.org/10.1093/ije/dys223

Sanders, C., Rogers, A., Bowen, R., Bower, P., Hirani, S., Cartwright, M., Fitzpatrick, R., Knapp, M., Barlow, J., \& Hendy, J. (2012). Exploring barriers to participation and adoption of telehealth and telecare within the Whole System Demonstrator trial: a qualitative study. BMC health services research, 12(1), 220. https://doi.org/10.1186/1472-6963-12-220

Scharf, T., \& Keating, N. C. (2012). From exclusion to inclusion in old age: A global challenge. Bristol: Policy Press.

Schmidt, L. I., \& Wahl, H.-W. (2018). Predictors of Performance in Everyday Technology Tasks in Older Adults With and Without Mild Cognitive Impairment. The Gerontologist, 59(1), 90-100. https://doi.org/10.1093/geront/gny062

Schnoll, H. J. (2014). E-Government : Information, Technology, and Transformation. Armonk, UK: Routledge.

Scott, B. K., Miller, G. T., Fonda, S. J., Yeaw, R. E., Gaudaen, J. C., Pavliscsak, H. H., Quinn, M. T., \& Pamplin, J. C. (2020). Advanced Digital Health Technologies for COVID-19 and Future Emergencies. Telemedicine and e-Health, 26(10), 12261233. https://doi.org/10.1089/tmj.2020.0140

Seaman, S. R., \& White, I. R. (2013). Review of inverse probability weighting for dealing with missing data. Statistical Methods in Medical Research, 22(3), 278-295. https://doi.org/10.1177/0962280210395740

Seifert, A. (2020). The Digital Exclusion of Older Adults during the COVID-19 Pandemic. Journal of Gerontological Social Work, 1-3. https://doi.org/10.1080/01634372.2020.1764687

Seifert, A., Cotten, S. R., \& Xie, B. (2020). A Double Burden of Exclusion? Digital and Social Exclusion of Older Adults in Times of COVID-19. The Journals of Gerontology: Series B. https://doi.org/10.1093/geronb/gbaa098 
Seifert, A., Hofer, M., \& Rössel, J. (2018). Older adults' perceived sense of social exclusion from the digital world. Educational Gerontology, 44(12), 775-785. https://doi.org/10.1080/03601277.2019.1574415

Seifert, A., Kamin, S. T., \& Lang, F. R. (2020). Technology Adaptivity Mediates the Effect of Technology Biography on Internet Use Variability. Innovation in Aging, 4(2). https://doi.org/10.1093/geroni/igz054

Settersten, R. A. (1999). Lives in time and place: The problems and promises of developmental science. New York: Routledge.

Shah, S. G. S., Robinson, I., \& AlShawi, S. (2009). Developing medical device technologies from users' perspectives: A theoretical framework for involving users in the development process. International Journal of Technology Assessment in Health Care, 25(4), 514-521. https://doi.org/10.1017/S0266462309990328

Siegel, C., \& Dorner, T. E. (2017). Information technologies for active and assisted living-Influences to the quality of life of an ageing society. International Journal of Medical Informatics, 100, 32-45. https://doi.org/10.1016/j.ijmedinf.2017.01.012

Silva, P., Matos, A. D., \& Martinez-Pecino, R. (2017). E-inclusion: Beyond individual socio-demographic characteristics. PLOS ONE, 12(9), e0184545. https://doi.org/10.1371/journal.pone.0184545

Sims, T., Reed, A. E., \& Carr, D. C. (2016). Information and Communication Technology Use Is Related to Higher Well-Being Among the Oldest-Old. The Journals of Gerontology: Series B, 72(5), 761-770. https://doi.org/10.1093/geronb/gbw130

Sixsmith, A., Mihailidis, A., \& Simeonov, D. (2017). Aging and Technology: Taking the Research into the Real World. Public Policy \& Aging Report, 27(2), 74-78. https://doi.org/10.1093/ppar/prx007

Subramanian, U., Hopp, F., Lowery, J., Woodbridge, P., \& Smith, D. (2004). Research in home-care telemedicine: challenges in patient recruitment. Telemedicine Journal \& e-Health, 10(2), 155-161. https://doi.org/10.1089/tmj.2004.10.155

Søgaard, A. J., Selmer, R., Bjertness, E., \& Thelle, D. (2004). The Oslo Health Study: The impact of self-selection in a large, population-based survey. International Journal for Equity in Health, 3(1). https://doi.org/10.1186/1475-9276-3-3

Tavares, L. P., \& Zantomio, F. (2017). Inequity in health care use among older people after 2008: The case of southern European countries. Health Policy, 121(10), 10631071. https://doi.org/10.1016/j.healthpol.2017.08.011

Taylor, J. S., DeMers, S. M., Vig, E. K., \& Borson, S. (2012). The disappearing subject: exclusion of people with cognitive impairment and dementia from geriatrics research. Journal of the American Geriatrics Society, 60(3), 413-419. https://doi.org/10.1111/j.1532-5415.2011.03847.x

Terraneo, M. (2015). Inequities in health care utilization by people aged 50+: Evidence from 12 European countries. Social Science \& Medicine, 126, 154-163. https://doi.org/10.1016/j.socscimed.2014.12.028

Thake, M., \& Lowry, A. (2017). A systematic review of trends in the selective exclusion of older participant from randomised clinical trials. Archives of Gerontology and Geriatrics, 72, 99-102. https://doi.org/10.1016/j.archger.2017.05.017

The EuroQol Group. (1990). EuroQol-a new facility for the measurement of healthrelated quality of life. Health policy, 16(3), 199-208. https://doi.org/10.1016/01688510(90)90421-9 


\section{References}

Thompson, K. M., Jaeger, P. T., Taylor, N. G., Subramaniam, M., \& Bertot, J. C. (2014). Digital literacy and digital inclusion: Information policy and the public library. Lanham: Rowman \& Littlefield.

Torres, S. (2015). Expanding the gerontological imagination on ethnicity: conceptual and theoretical perspectives. Ageing and Society, 35(5), 935-960. https://doi.org/10.1017/S0144686X14001330

Torres, S. (2019). Ethnicity and old age: Expanding our imagination. Bristol: Policy Press.

Townsend, P. (1981). The structured dependency of the elderly: a creation of social policy in the twentieth century. Ageing \& Society, 1(1), 5-28. https://doi.org/10.1017/S0144686X81000020

Tsai, H.-Y. S., Shillair, R., Cotten, S. R., Winstead, V., \& Yost, E. (2015). Getting Grandma Online: Are Tablets the Answer for Increasing Digital Inclusion for Older Adults in the U.S.? Educational Gerontology, 41(10), 695-709. https://doi.org/10.1080/03601277.2015.1048165

Tsertsidis, A., Kolkowska, E., \& Hedström, K. (2019). Factors influencing seniors' acceptance of technology for ageing in place in the post-implementation stage: A literature review. International Journal of Medical Informatics, 129, 324-333. https://doi.org/10.1016/j.ijmedinf.2019.06.027

United Nations. (2020). E-Government Survey 2020 - Digital Government in the Decade of Action for Sustainable Development. New York: United Nations.

United Nations Department of Economic and Social Affairs. (2020). World Social Report 2020: Inequality in a Rapidly Changing World: New York, UN.

United Nations Fund for Population Activities. (2020). Compendium of Digital Government Initiatives in response to the COVID-19 Pandemic. New York: United Nations Publications.

van Deursen, A., \& Helsper, E. J. (2015). A nuanced understanding of Internet use and non-use among the elderly. European Journal of Communication, 30(2), 171-187. https://doi.org/10.1177/0267323115578059

Van Deursen, A. J., \& Helsper, E. J. (2015). The third-level digital divide: Who benefits most from being online? Communication and information technologies annual, 10, 29-52. https://doi.org/10.1108/S2050-206020150000010002

van Deursen, A. J. A. M. (2020). Digital Inequality During a Pandemic: Quantitative Study of Differences in COVID-19-Related Internet Uses and Outcomes Among the General Population. J Med Internet Res, 22(8), e20073. https://doi.org/10.2196/20073

van Deursen, A. J. A. M., \& van Dijk, J. A. G. M. (2011). Internet skills performance tests: are people ready for eHealth? J Med Internet Res, 13. https://doi.org/10.2196/jmir.1581

van Dijk, J., \& Hacker, K. (2003). The Digital Divide as a Complex and Dynamic Phenomenon. The Information Society, 19(4), 315-326. https://doi.org/10.1080/01972240309487

van Gemert-Pijnen, J. E. W. C., Nijland, N., van Limburg, M., Ossebaard, H. C., Kelders, S. M., Eysenbach, G., \& Seydel, E. R. (2011). A Holistic Framework to Improve the Uptake and Impact of eHealth Technologies. J Med Internet Res, 13(4), e111. https://doi.org/10.2196/jmir.1672 
van Heuvelen, M. J. G., Hochstenbach, J. B. M., Brouwer, W. H., de Greef, M. H. G., Zijlstra, G. A. R., van Jaarsveld, E., Kempen, G. I. J. M., van Sonderen, E., Ormel, J., \& Mulder, T. (2005). Differences between participants and non-participants in an RCT on physical activity and psychological interventions for older persons. J Aging Clinical Experimental Research, 17(3), 236-245. https://doi.org/10.1007/bf03324603

Van Loon, A. J. M., Tijhuis, M., Picavet, H. S. J., Surtees, P. G., \& Ormel, J. (2003). Survey Non-response in the Netherlands: Effects on Prevalence Estimates and Associations. Annals of Epidemiology, 13(2), 105-110. https://doi.org/10.1016/S1047-2797(02)00257-0

Verheijden Klompstra, L., Jaarsma, T., \& Strömberg, A. (2014). Exergaming in older adults: a scoping review and implementation potential for patients with heart failure. European Journal of Cardiovascular Nursing, 13(5), 388-398. https://doi.org/10.1177/1474515113512203

Victor, C. (2010). The demography of ageing. In D. D. C. Phillipson (Ed.), The SAGE handbook of social gerontology (pp. 61-74). London: Sage Publishing.

Vroman, K. G., Arthanat, S., \& Lysack, C. (2015). "Who over 65 is online?” Older adults' dispositions toward information communication technology. Computers in Human Behavior, 43, 156-166. https://doi.org/10.1016/j.chb.2014.10.018

Walker, A. (1980). The social creation of poverty and dependency in old age. Journal of Social Policy, 9(1), 49-75. https://doi.org/10.1017/S0047279400009545

Walker, A. (2016). Reexamining the political economy of aging: understanding the

structure/agency tension. In D. D. Jan Baars, Chris Phillipson, \& Alan Walker (Ed.), Aging, globalization and inequality. The new critical gerontology. Amityville, NY: Baywood.

Walker, A., \& Foster, L. (2014). The Political Economy of Ageing and Later Life. Cheltenham Edward Elgar Publishing.

Watts, G. (2020). COVID-19 and the digital divide in the UK. The Lancet Digital Health, 2(8), e395-e396. https://doi.org/10.1016/s2589-7500(20)30169-2

Weiss, D., Rydland, H. T., Øversveen, E., Jensen, M. R., Solhaug, S., \& Krokstad, S. (2018). Innovative technologies and social inequalities in health: a scoping review of the literature. PloS one, 13(4), e0195447. https://doi.org/10.1371/journal.pone.0195447

Westwood, S. (2017). Ageing, diversity and equality: Social justice perspectives. Milton Park: Taylor \& Francis.

Wildman, J. M. (2020). "It's Luck as to What Sort of Family You're Born Into" Cumulative Dis/advantage Generative Systemic Processes Across the Life Course of a Baby-Boom Birth Cohort. The Journals of Gerontology: Series B, 75(6), 13021311. https://doi.org/10.1093/geronb/gbaa017

Williams, B., Irvine, L., McGinnis, A. R., McMurdo, M. E., \& Crombie, I. K. (2007). When "no" might not quite mean "no"; the importance of informed and meaningful non-consent: results from a survey of individuals refusing participation in a healthrelated research project. BMC Health Services Research, 7(1), 59. https://doi.org/10.1186/1472-6963-7-59

Wilson, G., Gates, J. R., Vijaykumar, S., \& Morgan, D. J. (2021). Understanding older adults' use of social technology and the factors influencing use. Ageing and Society, 1-24. https://doi.org/10.1017/S0144686X21000490 


\section{References}

World Health Organization. (2017). Global diffusion of eHealth-making universal health coverage achievable: report of the third global survey on eHealth (9789241511780). Retrieved from https://apps.who.int/iris/handle/10665/252529

Yang, R., Carter, B. L., Gums, T. H., Gryzlak, B. M., Xu, Y., \& Levy, B. T. J. B. M. R. M. (2017). Selection bias and subject refusal in a cluster-randomized controlled trial. 17(1), 94. https://doi.org/10.1186/s12874-017-0368-7

$\mathrm{Yu}, \mathrm{K}$., Wu, S., \& Chi, I. (2020). Internet Use and Loneliness of Older Adults Over Time: The Mediating Effect of Social Contact. The Journals of Gerontology: Series B. https://doi.org/10.1093/geronb/gbaa004

Yu, R. P., Ellison, N. B., McCammon, R. J., \& Langa, K. M. (2016). Mapping the two levels of digital divide: Internet access and social network site adoption among older adults in the USA. Information, Communication \& Society, 19(10), 1445-1464. https://doi.org/10.1080/1369118X.2015.1109695

Yun, J. E., Park, J.-E., Park, H.-Y., Lee, H.-Y., \& Park, D.-A. (2018). Comparative Effectiveness of Telemonitoring Versus Usual Care for Heart Failure: A Systematic Review and Meta-analysis. Journal of Cardiac Failure, 24(1), 19-28. https://doi.org/10.1016/j.cardfail.2017.09.006 
Arianna Poli 


\section{Papers}

The papers associated with this thesis have been removed for copyright reasons. For more details about these see:

http://urn.kb.se/resolve?urn=urn:nbn:se:liu:diva-178298 


\section{FACULTY OF ARTS AND SCIENCES}

Linköping Studies in Arts and Sciences No. 814, 2021

Division Ageing and Social Change (ASC)

Department of Culture and Society [IKOS]

Linköping University

SE-581 83 Linköping, Sweden

www.liu.se 